This submission should be considered as part of the "Diamond Wing Aerodynamics" special issue.

\title{
Vortical Flow Prediction of a Diamond Wing with Rounded Leading Edges
}

\author{
Mehdi Ghoreyshi ${ }^{1}$, Krzysztof Ryszka, Russell M. Cummings, and Andrew J. Lofthouse \\ High Performance Computing Research Center, U.S. Air Force Academy \\ USAF Academy, Colorado 80840-6400, USA
}

\begin{abstract}
The objective of this work is to assess the potential and limitations of current practice in computational fluid dynamic modeling in predicting vortical flowfields over a generic 53degree swept diamond wing with rounded leading edges. This wing was designed under STO AVT Task Group 183 and has a constant NACA 64A-006 airfoil section with a leading edge radius of 0.264 percent chord. CFD simulations were run for different angles of attack at a Mach number of 0.15 and a Reynolds number of $2.7 \times 10^{6}$ based on the mean aerodynamic chord to match experiments. The wind tunnel experiments of the diamond wing were carried out in the Institute of Aerodynamics and Fluid Mechanics of the Technische Universität München, Germany and include aerodynamic lift, drag, and pitch moment measurements as well as span-wise pressure distributions at different chord-wise locations. This data set is used to validate the CFD results. The results presented demonstrate that the CFD compare well with the experiments at small angles of attack; the pitch moments predicted by the SARC turbulence model provide a better match to experimental results than the SA model at moderate angles of attack; and at high angles of attack, CFD predictions are not as good. The flow visualization results show that a leading-edge vortex is formed above the upper surface of the wing at an angle of attack of about eight degrees. This vortex becomes larger and stronger when the angle of attack is increased. With increasing angle of attack, the vortex formation point moves upstream and the vortex core moves inboard towards the wing center. Finally, the computational results show that the flow over the diamond wing is relatively steady throughout the range of angles of attack.
\end{abstract}

Keywords:

Diamond wing, Vortical Flow, Validation, Swept wings with rounded leading edges

\footnotetext{
Email address: Mehdi.Ghoreyshi@usafa.edu (Mehdi Ghoreyshi)

${ }^{1}$ Corresponding Author.

"The views expressed in this paper are those of the author and do not reflect the official policy or position of the United States Air Force, Department of Defense, or the U.S. Government." Distribution A. Approved for Public Release. Distribution unlimited.
}

Preprint submitted to Aerospace Science and Technology

February 5, 2016 


\section{Nomenclature}

$\begin{array}{ll}a & \text { speed of sound, } \mathrm{m} / \mathrm{s} \\ C_{f} & \text { skin friction coefficient, } F / q_{\infty} S \\ C_{L} & \text { lift coefficient, } L / q_{\infty} S \\ C_{m} & \text { pitch moment coefficient, } \bar{M} / q_{\infty} S c \\ C_{p} & \text { pressure coefficient, }\left(p-p_{\infty}\right) / q_{\infty} \\ c & \text { mean aerodynamic chord, } \mathrm{m} \\ c_{r} & \text { chord length at wing root, } \mathrm{m} \\ F & \text { skin friction force, } \mathrm{N} \\ L & \text { lift force, } \mathrm{N} \\ M & \text { Mach number, } \mathrm{V} / \mathrm{a} \\ \bar{M} & \text { pitch moment, } \mathrm{N}-\mathrm{m} \\ p & \text { static pressure, } \mathrm{Pa} \\ p_{\infty} & \text { freestream pressure, } \mathrm{Pa} \\ q_{\infty} & \text { dynamic pressure, } \mathrm{Pa}, \rho V^{2} / 2 \\ R e & \text { Reynolds number, } \rho V c / \mu \\ S & \text { planform area, } \mathrm{m}^{3} \\ s & \text { semi span, m } \\ t & \text { time, } \mathrm{s} \\ V & \text { freestream velocity, m/s } \\ x, y, z & \text { aircraft position coordinates }\end{array}$

\section{Greek}

$\begin{array}{ll}\alpha & \text { angle of attack, rad } \\ \beta & \text { side-slip angle, rad } \\ \rho & \text { air density, } \mathrm{kg} / \mathrm{m}^{3} \\ \mu & \text { air viscosity, } \mathrm{kg} /(\mathrm{m} . \mathrm{s})\end{array}$

\section{Introduction}

Today's modern fighter aircraft typically employ a delta wing configuration to reduce the wave drag at supersonic speeds. The aerodynamic performances of these delta wings are vastly different from those known for the high-aspect ratio wings. In the latter case, the lift increases linearly with angle of attack in the attached flow region and then sharply decreases in the post-stall region [1]. The lift of a sharp delta wing has also an initial linear increase, but at an angle of attack of just few degrees there is an additional lift force to the attached flow lift which makes the lift-curve slope nonlinear. This additional lift, often called the vortex lift, is caused by the vortical flows formed above the wing [2]. The flow separation point of a sharp delta wing is fixed at the leading edge [2]. This creates a strong shear layer along the wing edges which will then roll up into a pair of counter-rotating vortices over 
the upper surface on the two halves of the wing [3]. These vortices are called leading-edge vortices and their structures depend on the wing's sweep angle, leading-edge geometry, wing thickness, and freestream conditions [4].

For a sharp-edged delta wing, the separation points are fixed at the leading edge for a considerable range of angle of attack [5]. The vortex strengths and vortex lift will therefore increase with the increase in the angle of attack. At higher angles, however, vortices experience an abrupt transformation called the vortex breakdown which is an asymmetric phenomenon. In a vortex breakdown, the axial velocity component suddenly decelerates and the swirl component of the mean velocity decreases due to the vortex core expansion [6]. The asymmetric vortex breakdown conditions result in additional moments in pitch, yaw, and roll with magnitudes as large or even larger than those obtained from traditional control surface deflections. The vortex breakdown may result sudden changes in pitch moment, loss of lift, and buffeting [7]. The stability and control (S\&C) and structural analysis of delta wings are therefore highly dependent on the ability to observe and accurately calculate the principle characteristics of vortical flows.

While the vortical flow behavior over slender wings with sharp leading edges has been studied extensively for over last few decades [8, 9, 10], much less is known about the formation of vortices over wings with lower sweep angles and blunt leading edges. These type of wings are often incorporated in the designs of unmanned combat aircraft vehicles (UCAV) [11]. For these wings, the vortex flow structure is very complicated and depends heavily on the leading edge bluntness and the wing sweep angle. For delta wings with blunt tips, the leading edge separation point is also very sensitive to the boundary layer changes [12]. The blunt tip vortices can also have significant effects on the stability and control characteristics of a maneuvering aircraft at high angles of attack. The objective of this work is to assess the potential and limitations of current practice in computational fluid dynamics (CFD) modeling for predicting vortical flowfields over a generic 53-degree swept diamond wing with blunt tips.

The diamond wing considered in this work was designed under STO AVT Task Group 183. The wing planform is based on the SACCON UCAV geometry. The SACCON wing trailing-edge was swept forward by 26.5-degrees to form a diamond-shaped planform. The new wing has a constant airfoil section of NACA 64A-006 with a leading edge radius of 0.264 in percent chord. The wind tunnel experiments of the diamond wing were carried out in the Institute of Aerodynamics and Fluid Mechanics of Technische Universität München, Germany and include aerodynamic lift, drag, and pitch moment measurements as well as span-wise pressure distributions at different chord-wise locations. This data set is used to validate CFD results.

This work is organized into four major categories. First a survey of the literature and theories pertaining to the delta wing vortical flows is provided. The flow solver is then briefly described. Next, the test case is presented and the experimental setup is detailed. Finally, the simulation results will be discussed. 


\section{Vortical Flows}

The vortical flow behavior over delta wings is extremely complex and differs substantially from sharp to blunt tipped wings and from nonslender to slender wings. Over the past few decades, most research on vortical flows was done on the vortices over slender sharp-edged delta wings [13]. Some early works in this field were reviewed by Sun [14] and most recently by Mitchell et al. [4]. In one of the earliest studies, Jensen (1948) [15] studied the low-speed flowfields and the lift and moment characteristics of a sweptback wing and a delta wing, both with a $65^{\circ}$ sweptback leading edge and a double wedge symmetrical airfoil section. His results showed that two strong vortices are formed over the upper surfaces of both wings for angles of attack as low as $10^{\circ}$. A sketch of these vortices is shown in Figure 1 for the delta wing case. Jensen's work also showed that the lift curve slope increases for angles of attack above ten degrees.

It is well known that a sharp leading edge causes the boundary layer to separate at the leading edge resulting a free shear layer. For a slender wing, the separated shear layers roll up into a pair of counter-rotating vortices over the upper surface on the two halves of the wing. The shear layer may exhibit instabilities that increase the vortical substructures and, therefore, the primary vortex increases in both size and strength as it extends downstream. Ornberg [16] in 1954 showed that these leading edge vortices are stationary and form a low pressure region over the upper surface that will increase the lift. Notice that this additional lift comes at the expense of a drag penalty due to loss of leading-edge suction [17]. The leading edge vortices allow the onset of stall to be delayed to higher angles as well. For steady and inviscid flow, the vortex lift can be approximated to some extent by the leading edge suction analogy [18], linear slender wing theory [19], or detached flow methods [20]. The Polhamus's leading edge suction analogy is probably the most widely applicable method to estimate the vortex lift of different planforms at different flight speeds. This analogy assumes that the vortex lift has the same magnitude as the potential-flow force which is lost because of the separation at the sharp leading edge [21]. The method has provided good results for attached vortices [18].

As the angle of attack increases, the cores of leading edge vortices will move inboard and secondary vortices can be formed below the main vortices [22]. Ornberg [16] in 1954 and Marsden et al. [23] in 1958 found the existence of these secondary vortices. They found that the secondary vortices form below and outboard of primary vortices with opposite circulation. Specifically, the primary vortices may separate near the wing surface because of the adverse pressure gradients in the spanwise direction [23]. These separated flows may then roll up to form smaller secondary vortices of the opposite sign of vorticity which tend to move the primary vortices inboard and upward [7].

Leibovich [24] showed that for a slender delta wing, each leading-edge vortex core is approximately one core diameter above the lifting surface of the wing. Over a nonslender wing, however, the vortices are formed much closer to the surface of the wing, therefore, the interaction of the secondary vortices with the shear layer of the primary vortex causes the primary vortex to split into a dual primary vortex structure [25]. Since the cores of vortices over nonslender wing are much closer to the surface and its boundary layer, the flow over 
nonslender wings is more sensitive to Reynolds number than flows over slender wings [25]. The vortical flow separation also occurs at lower angles of attack compared with a slender delta wing [11].

The leading-edge vortices have significant effects on the aerodynamic behavior of aircraft; they form regions of high vorticity and low-pressure over the upper wing surface that cause a nonlinear increase in lift until the maximum attainable lift with attached flow [8]. At high angles of attack, the vortex structures change dramatically, leading to vortex breakdown, which is known to cause nonlinear aerodynamic behavior. Vortex breakdown is characterized by a sudden deceleration of the axial flow in the vortex core, a decrease in circumferential velocity, and an increase in the vortex size and turbulent dissipation [26]. The onset of vortex breakdown starts from the trailing edge of the wing and moves forward on the wing with increasing angle of attack until, at sufficiently high angle of attack, the flow is dominated by the periodic wake shedding encountered over bluff bodies [27]. Note that a slender wing attains its maximum lift and stalls approximately when the onset of vortex breakdown crosses the trailing edge, while wings with smaller sweep angles stall when the onset of vortex breakdown moves towards the wing apex [26].

One of the methods to reduce the vortex drag is using a rounded leading edge [28]. While the leading edge suction is (normally) lost in the sharp edges, a large portion of the leading-edge suction is restored in a round edge and hence the drag force becomes smaller. However, the blunt tips fundamentally change the vortical flow behavior and structure. On delta wings with rounded leading edges, the flow separation point is not fixed at the leading edge and depends on the Reynolds number and the leading edge curvature. The origin of the leading edge vortex is at the delta wing apex for a sharp-edged wing but it is further downstream for a rounded tip [29]. The leading-edge vortices from sharp edges are steady for a wide range of angles of attack. Only if the angle of attack increases greatly, these vortices become unsteady and separate starting from the trailing edge of the wing. The flow at blunt nose, however, separates at moderate to high angles of attack starting from an outboard and aft location near the trailing edge [29]

\subsection{CFD Solvers}

Cobalt and Kestrel flow solvers are used in this work. Both codes originated from the Air Vehicles Unstructured Solver (AVUS, formally known as Cobalt60) that was developed at the Air Force Research Laboratory (AFRL) [30, 31, 32]. Cobalt is now a commercial code whilst Kestrel is being developed by the U.S. Department of Defense as part of the CREATE $^{\mathrm{TM}}$-AV program.

Both codes solve the unsteady, three-dimensional and compressible Navier-Stokes equations in an inertial reference frame. The Navier-Stokes equations are discretized on arbitrary grid topologies using a cell-centered finite volume method. The foundation of the inviscid solver is Godunov's first-order exact Riemann method [33]. Second-order accuracy in space is achieved using the exact Riemann solver of Gottlieb and Groth [34], and least squares gradient calculations using QR factorization. To accelerate the solution of the discretised system, a point-implicit method using analytic first-order inviscid and viscous Jacobians is implemented. A Newtonian sub-iteration method can be employed to improve time accuracy 
of the point-implicit method. Both Cobalt and Kestrel have a range of turbulence models available for use including the Reynolds-Averaged Navier-Stokes (RANS) method and also the hybrid delayed detached eddy simulation (DDES) method. The turbulence models of Spalart-Allmaras (SA) [35] and SA with a rotation and curvature correction (SARC) [36] are used in this work.

\section{Test Case}

The diamond wing used for this work was designed within the NATO RTO task group AVT-183. The objective of this task group was reliable prediction of separated flow onset and progression for air and sea vehicles. The AVT-183 wing is based on the SACCON UCAV geometry of the AVT-161 research program [37] but it retains a simple and less complicated design compared to SACCON. In more details, the SACCON has a lambda wing planform with a leading edge sweep angle of $53^{\circ}$ as shown in Fig. 2. The main sections of the SACCON model are the fuselage, the wing section, and wing tip. The configuration is defined by three different profiles at the root section of the fuselage, two sections with the same profile at the inner wing, forming the transition from the fuselage to wing and the outer wing section.

The spanwise distributions of thickness in percent chord and leading-edge radius of SACCON are shown in Figure 3. According to this figure, the leading edge radius is sharp at the root chord and then increases in the spanwise direction up to the intersection between fuselage and wing and then decreases. Figure 3 also shows that the thickness ratio in spanwise direction decreases. Finally, the outer wing section profile is twisted by $5^{\circ}$ around the leading edge to reduce the aerodynamic loads and shift the onset of flow separation to higher angles of attack.

The combination of sweep angle with sharp-blunt leading edges and the twist angle makes the flow around SACCON very complicated and difficult to predict even for static conditions $[38,39,40]$. This is due to formation of an apex vortex and a tip vortex which are formed by the onset and progression of the flow at the sharp and blunt leading edges at moderate angles of attack. At higher angles of attack these vortices become stronger and the onset of the tip vortex moves inboards. Over a small range of angle-of-attack, two vortices merge and coalesce to form much a stronger and deeper vortex which suddenly changes the pitch moment values. At higher angles, vortices breakdown and again cause severe pitch moment changes.

For all the above reasons, while CFD results of AVT-161 match each other at small angles of attack, they predicted different values at moderate to high angles of attack; none of codes could match the SACCON experimental data for the full range of angles of attack. To follow up the vortex flow studies of AVT-161 and gain information to understand why some CFD codes miss or match the leading-edge separation aerodynamics of interest, the work of AVT183 has been focused on a new geometry with simpler design complexity than the SACCON. The new wing has a constant radius blunt leading edge in spanwise direction. The thickness ratio is also constant and the wing is non-twisted. In addition, the trailing edge has swept forward 26.5-degrees to form a diamond wing. This design has been compared with the SACCON geometry in Fig. 4. 
Figure 5 shows the diamond wing layout used in the wind tunnel experiments. The wind tunnel model was placed on a peniche with height of $9 \mathrm{~cm}$ to minimize the boundary layer effects from the wing tunnel wall. Figure 5 shows that the wind tunnel model of the wing has a root chord of $1.2 \mathrm{~m}$, slightly bigger than SACCON. The wing half span is approximately $0.65 \mathrm{~m}$. The moment reference point $\left(x_{\mathrm{mrp}}\right)$ is located at $0.49 \mathrm{~m}$ from the wing apex. A constant NACA64A006 airfoil section was used. The airfoil sections at three spanwise locations are shown in Figure 6.

A hybrid RANS mesh was generated for this model. The mesh was generated in two steps. In the first step, the inviscid tetrahedral mesh was generated from a clean configuration using the ICEM-CFD code. The inviscid mesh was then used as a background mesh by TRITET [41, 42] which builds prism layers using a frontal technique. TRITET rebuilds the inviscid mesh while respecting the size of the original inviscid mesh from ICEM-CFD. Mesh overview is shown in Figure 7. The grid has a symmetric configuration and contains 5.4 million points and 13.2 million cells.

\section{Wind Tunnel Experiments}

A half model of the diamond wing was built for wind tunnel testing. The model layout is shown in Figure 5. The experiments of the diamond wing were carried out at the Technische Universität München subsonic wind tunnel. Figures 8 shows the wing model with a peniche in the test section of this wind tunnel. The wind tunnel is operable in a closed- and opencircuit mode. The test section area is $1.80 \mathrm{~m} \times 2.40 \mathrm{~m}$ with a length of 4.8 meters. The wind tunnel maximum speed is about $65 \mathrm{~m} / \mathrm{sec}$.

All experiments were conducted for an angle of attack sweep at a Mach number of 0.15 and a Reynolds number of $2.7 \times 10^{6}$ based on the mean aerodynamic chord of $c=0.8 \mathrm{~m}$. To maintain turbulent flow at these low speeds and in ambient condition changes, transition trip dots were added to the diamond wing near the leading-edge [43].

An external six-component balance was used to measure the forces and moments acting on the model only and not the peniche. A stereo particle image velocimetry (PIV) technique was also used to measure flow field properties and detect vortical flows. The PIV technique was done with a laser and two cameras. The camera and laser positions are highlighted in Figure 8. For each test with different camera angles, about 400 images were captured. These images were processed using LaVision'DaVis software. The experimental data include averaged lift, drag, and pitch moment coefficients for all test runs over the range of tested angles of attack. Besides, the surface pressure coefficients were measured at different chordwise locations. These locations are shown in Figure 9.

\section{Results and Discussion}

Simulation conditions correspond to a Mach number of 0.15 and a Reynolds number of $2.7 \times 10^{6}$ based on the mean aerodynamic chord of $c=0.8 \mathrm{~m}$ to match experimental conditions. Steady and unsteady simulations of the diamond wing were carried out with 
different turbulence models and CFD solvers. All simulations used second-order spatial accuracy and an implicit temporal operator to advance the flow solution in time. However, the steady-state cases are first-order accurate in time and were computed with a CFL number of one-million. Unsteady computations were performed using second-order temporal accuracy and three Newton sub-iterations based on our experience with aerodynamic predictions of similar vehicles. Notice that larger Newton sub-iterations will increase the computational cost. The effects of the time step on the predictions were evaluated for unsteady simulations as well. Time step values used are $2 \times 10^{4}$ and $4 \times 10^{5}$ seconds which correlate to CFL numbers of 9.0 and 1.8 , respectively.

The turbulence models considered include the SA model, SARC, and DDES-SARC [44]. Although, RANS models remain popular, hybrid RANS/LES (large-eddy simulation) models are still required for predicting unsteady separated flows. One hybrid RANS/LES approach is the Delayed Detached-Eddy Simulation (DDES) model originally proposed by Spalart et al [44]. In this model, a turbulence model is applied to the boundary layer region and LES is used for the separated regions. The approach is substantially less costly than LES, while it can achieve better accuracy than the RANS turbulence model for predicting separated flows [45]. Hoping that the DDES formulation will improve predictions of flows with massive separation which occur in a time-dependent manner, DDES simulations were performed in this work as well. All these simulations use second-order temporal accuracy and three Newton sub-iterations.

The computed overall lift, drag, and pitch moment coefficients using the SA turbulence model and Cobalt code are shown in Figure 10 and compared to experimental data. These simulations are steady-state and correspond to an angle-of-attack sweep from 0 to $20^{\circ}$ with a 0.5 degrees increment for the angles between 8 to 16 degrees and one degree increment for all other angles. Two CFD data sets are presented in Figure 10; in the first, simulations ran for 1,500 iterations at all angles of attack; the second dataset corresponds to simulations that ran for 3,000 iterations at some high angles of attack. Figure 10 shows that the computed overall lift, drag, and pitch moment coefficients from both simulations match very well, indicating that the force and moment coefficients have already reached their final values at iteration 1,500 and they do not change further in time.

Figure 10 shows that predictions of Cobalt using the SA turbulence model match very well with experiments at small angles of attack but they do not match as well at higher angles, except for the drag force. At high angles of attack, Cobalt lift predictions overestimate and pitch moment predictions underestimate the measurements; also the experiments show that there is a break in the pitch moment curve around $8^{\circ}$ angle of attack. The Cobalt predictions using the SA model, however, show the break in pitch moment curve at a much higher angle (about $12^{\circ}$ ).

Results of steady-state simulations with the SARC turbulence models are compared with experiments and predictions obtained from the SA model in Figure 11. This figure also shows Kestrel predictions. All simulations were again first-order accurate in time and were computed with a CFL number of one million. Figure 11 shows that Cobalt and Kestrel predictions using the SA turbulence mode agree with each other at most angles of attack, particulary for lift and drag predictions. Differences between SA and SARC predictions 
were found to be small for Kestrel. Figure 11 also shows that the SARC and SA turbulence model predictions using Cobalt are in good agreement with each other and experiments at small angles of attack. However, at moderate to high angles, Cobalt predictions from these turbulence models are different: the SARC drag values are slightly larger than the SA model and experiments; the lift coefficients from the SARC model are slightly smaller than predicted lift from the SA model and become closer to the experiments for angles of attack above 15 degrees. The SARC pitch moment values agree well with experiments at moderate angles of attack but they are off for angles above 15 degrees. The SARC model in Cobalt accurately predicts the pitch moment break seen in the experiments. For this reason, Cobalt and SARC turbulence model are used in subsequent predictions.

Figure 12 shows the effects of the time step size in the unsteady SARC computations compared with the steady SARC predictions using Cobalt. Unsteady computations were performed using second-order temporal accuracy and three Newton sub-iterations with time step sizes of $2 \times 10^{-4}$ and $4 \times 10^{-5}$ seconds. These unsteady simulations were ran for 6,000 iterations and the overall forces and moments were averaged for the last 3,000 iterations. The results in Figure 12 reveal that discrepancies between the steady and unsteady predictions are very small. Additionally, Figure 13 shows the time histories of the lift and pitch moment coefficients with a time step of $4 \times 10^{-5}$ seconds at $\alpha=16^{\circ}$. This figure also shows the variations in lift coefficient for final 3,000 time steps, though they are small.

Figure 14 presents the flow visualization around the diamond wing at different angles of attack by using the SARC turbulence model and Cobalt code. At six degrees angle of attack, the flow separates at the wing-tip near trailing edge due to considerable pressure difference between the lower and upper surfaces. This separated flow then rolls up into a small-size tip vortex which can be seen in Figure 14 (a). At about $8^{\circ}$ angle of attack, a leading edge vortex is formed above the wing. This leading-edge vortex originates from about $0.4 c_{r}$ (the chord length at the wing root). The break seen in the pitch moment plot at $8^{\circ}$ angle of attack was caused by the formation of the leading-edge vortex. This vortex merges with the tip vortex and a low pressure region is formed above the upper surface around the vortex core. Vortices also increase in size as they extend downstream. As the angle of attack is further increased, the leading-edge vortices become stronger and bigger; the vortex formation point also moves upstream. The center of the vortex also moves inboard with increasing angle of attack. At high angles of attack the peniche vortex is visible in the solutions.

More details of the flows around the diamond wing can be found in Figures 15-22 which compare predicted pressure coefficients by the SA and SARC models with experiments for several angles of attack. In these figures, the corresponding pressure distributions on the upper and lower surfaces of the wing are shown. Figure 15 shows that at all chord-wise locations, shown in the figure for $\alpha=4^{\circ}$, CFD predictions from both turbulence models match well with each other and experiments. In all plots of this figure, moving towards the wing tip (i.e. $y / s=1$ ) a positive and a negative pressure gradient exist at the lower and upper surface, respectively. The pressure coefficient curves for $\alpha=4^{\circ}$ are smooth with a minimum pressure at the wing tip. Figure 15 shows that no vortex-type flow is present for the range of chordwise locations considered.

Figure 16 compares the pressure distribution plots at $\alpha=6^{\circ}$. The pressure differences 
between the upper and lower surfaces are larger than plots at $\alpha=4^{\circ}$. CFD pressure values match with experiments almost everywhere. The largest discrepancies in plots can be seen at $0.6 c_{r}$. At this location, the SARC model predicts a negative pressure coefficient region in the upper surface near the wing tip due to the tip vortex presence; the vortex core is located about $y / s=0.93$. However, $\mathrm{SA}$ and experiment results do not predict the existence of such a vortex at this location and angle. Figure 16 shows that at $0.6 c_{r}$, there is a positive spanwise pressure gradient towards the wing tip at the vortex boundaries. The lower surface pressure distributions at this angle of attack are smooth and have no interesting flow features present.

The pressure differences between the upper and lower surfaces at $\alpha=8^{\circ}$ even become larger. The lower surface pressure distributions show no interesting flow feature again as shown in Figure 17. However, the upper surface has a strong negative dip at some chordwise locations due to the presence of a leading edge vortex. The SARC model exhibits the vortex presence even at $0.395 c_{r}$. As flow moves downstream, the predicted vortex becomes bigger (the dip becomes wider), however the pressure values become less negative. The SA predicts a vortex above the upper surface as well. This vortex is seen only at $0.6 c_{r}$. Experiment results also exhibit a vortex starting around $0.5 c_{r}$. Figure 17 shows that pressure distributions predicted by CFD do not exactly match with experiments at and around vortex locations.

As angle of attack is increased to $\alpha=10^{\circ}$, the SARC predicted vortex starting point moves further upstream to about $0.295 c_{r}$ as shown in Figure 18. The vortex core also moves inboard towards the wing center. For example, Figure 17 shows that for $\alpha=8^{\circ}$ at $0.395 c_{r}$, the vortex core is located about $y / s=0.95$; the vortex core is located at about $y / s=0.85$ for $\alpha=10^{\circ}$. Experimental results show a vortex is formed starting at $0.395 c_{r}$. The SA model predicts the vortex starting point at $0.5 c_{r}$. CFD data and experimental results show that the predicted vortex becomes larger in size and the pressure values become less negative as the flow moves upstream. Also, a positive spanwise pressure gradient is predicted towards the wing tip at the vortex boundaries by the simulation and experimental results.

At 12 degrees angle of attack, experimental results show a vortex starting at $0.395 c_{r}$; the SARC and SA vortices now originate from $0.295 c_{r}$ and $0.395 c_{r}$, respectively. The vortices become bigger and induce more negative pressure regions as shown in Figure 19. For example, at $0.6 c_{r}$ the vortex diameter is about 0.4 of half-span length. As the angle of attack is further increased, vortices predicted from CFD and experiments become much bigger. At high angles of attack, the pressure distribution becomes more uniform across the vortex at upstream locations. Figures 20-22 show that for angles of attack greater than $14^{\circ}$, CFD predictions using the SARC turbulence model look inferior to the SA predictions. In more detail, Figure 23 compares the SA and SARC flow solutions at $\alpha=16^{\circ}$. Figure shows that the SARC model predicts much stronger vortices over the wing than the SA model. The $\mathrm{SARC}$ even predicts a peniche vortex at this angle, whereas no peniche vortex was found using the SA turbulence model.

Final results compare CFD predictions using DDES-SARC turbulence model with experiments. DDES simulations ran for 12,000 iterations using a second-order time accuracy and a time step of $4 \times 10^{-5}$ second. Lift, drag, and pitch moment coefficients were averaged for the last 6,000 iterations. Figure 24 compares the DDES-SARC predictions with experiments 
as well as the SARC predictions. The results show that predictions from the DDES-SARC model do not match with experiments; the prediction curves are not smooth as well. Notice that the flow is steady-state at these angles as shown earlier and a DDES model probably do not much help to improve predictions. Note that DDES predictions largely depend on the grid spacing and the prediction of the boundary layer.

To compare the CFD predictions of this work with predictions made by other codes in the AVT-183 Task Group, Figure 25 shows the flow analysis and visualization of the diamond wing at 12 degrees angle of attack. Figure 25 (a) shows the flow streamlines and pressure coefficients over the upper surface around the leading edge. There is a thin region of rotating flow at where the upper and lower surfaces meet. On the upper surface, at a point of about $(0.3,0.219,0) \mathrm{m}$, the flow separates from the surface and rolls up into a leading-edge vortex; the core of this vortex is clearly shown in Fig. 25 (a). The vortex structure can be seen in Fig. 25 (b). Figure 25 (c) shows the turbulent eddy viscosity ratio around the wing surface. Notice that strong eddy viscosity values are produced in the leading-edge vortex. The upper surface pressure and skin friction coefficients are also shown in Figs. 25 (d) and (e), respectively. Finally, Fig. 25 (f) shows the flow vectors at $x=0.7 \mathrm{~m}$ at 12 degrees angle of attack. The leading-edge vortex can be clearly seen in this figure.

\section{Conclusions}

While the vortical flow behavior over slender wings with sharp leading edges has been studied extensively for the last few decades, much less is known about the formation of vortices over wings with lower sweep angles and blunt leading edges. In the latter, the vortex flow structure is very complicated and depends heavily on the leading edge bluntness and the wing sweep angle. These vortices can have significant effects on the aircraft stability and control characteristics.

CFD potential and limitations for predicting vortical flowfields were investigated over a generic 53-degree swept diamond wing with blunt tips. The diamond wing considered in this work was designed under STO AVT Task Group 183. The wing planform is based on the SACCON UCAV geometry. The SACCON wing trailing-edge was swept forward by 26.5degrees to form a diamond-shaped planform. The new wing has a constant airfoil section of NACA $64 \mathrm{~A}-006$ with a leading edge radius of 0.264 in percent chord. The wind tunnel experiments of the diamond wing were carried out in the Institute of Aerodynamics and Fluid Mechanics of Technische Universität München, Germany and include aerodynamic lift, drag, and pitch moment measurements as well as span-wise pressure distributions at different chord-wise locations. This data set is used to validate CFD results.

Turbulence models considered included the SA model, SARC, and DDES with SARC. The results presented demonstrated that the pitch moments predicted by the SARC turbulence model provided a better match to experimental results than the SA model at moderate angles of attack. However, at high angles of attack, all pitch moment predictions were off. The flow visualization results showed that a leading-edge vortex is formed above the upper surface of the wing at an angle of attack about eight degrees. This vortex became larger and stronger as the angle of attack was increased. With increasing angle of attack, 
the vortex starting point moved upstream and the vortex core moved inboard towards the wing root. The static pressure data showed that the SARC model predicts the leading-edge vortex at smaller angles of attack with a starting point further upstream compared to the experiments. On the other hand, the SARC model predicts at higher angles of attack with a starting point further downstream compared to the experiments. The results also showed that for the range of angles of attack considered in this work, the flow over the diamond wing was relatively steady, because the vortices were attached and stationary at each angle of attack. For this reason, predictions from the DDES-SARC model also did not match as well with experiments.

\section{Acknowledgements}

Mehdi Ghoreyshi was supported by USAFA under contract FA70001320018; their financial support is gratefully acknowledged. Computer time was provided by the Department of Defense Engineering Research Development Center (ERDC). The experimental data were provided in the framework of STO AVT Task Group 183 by the Institute of Aerodynamics and Fluid Mechanics of the Technische Universität München, München, Germany. The authors appreciate the support provided by the High Performance Computing Research Center at USAFA.

\section{References}

[1] Torenbeek, E. and Wittenberg, H., Flight Physics: Essentials of Aeronautical Disciplines and Technology, with Historical Notes, Springer, 2009.

[2] Gad-el Hak, M. and Blackwelder, R. F., "The Discrete Vortices From a Delta Wing," AIAA Journal, Vol. 23, No. 6, 1985, pp. 961-962, DOI: 10.2514/3.9016.

[3] Houghton, E. L., Carpenter, P. W., Collicott, S., and Valentine, D., Aerodynamics for Engineering Students, Elsevier, 2013.

[4] Mitchell, A., Molton, P., Barberis, D., and Delery, J., "Vortical Substructures in the Shear Layers Forming Leading-Edge Vortices," AIAA Paper 2001-2424, June 2001.

[5] Mangler, K. W. and Smith, J. H. B., "A Theory of the Flow Past a Slender Delta Wing with Leading Edge Separation," Proceedings of the Royal Society of London. Series A, Mathematical and Physical Sciences, Vol. 251, No. 1265, 1959, pp. 200-217.

[6] Morton, S., Forsythe, J. R., Mitchell, A. M., and Hajek, D., "DES and RANS Simulations of Delta Wing Vortical Flows," AIAA Paper 2002-0587, January 2002.

[7] Agrawal, S., Barnett, R. M., and Robinson, B. A., "Numerical Investigation of Vortex Breakdown on a Delta Wing," AIAA Journal, Vol. 30, No. 3, 1992, pp. 584-591.

[8] Thomas, J. L., Krist, S. T., and Anderson, W. K., "Navier-Stokes Computations of Vortical Flows Over Low-Aspect-Ratio Wings," AIAA Journal, Vol. 28, No. 2, 1990, pp. 205-212.

[9] Gursul, I., Gordnier, R., and Visbal, M., "Unsteady Aerodynamics of Nonslender Delta Wings," Progress in Aerospace Sciences, Vol. 41, 2005, pp. 515557.

[10] Vallespin, D., Da Ronch, A., Badcock, K. J., and Boelens, O. J., "Vortical Flow Prediction Validation for an Unmanned Combat Air Vehicle Model," Journal of Aircraft, Vol. 48, No. 6, 2011, pp. $1948-1959$.

[11] Elsayed, M., Scarano, F., and Verhaagen, N. G., "Leading-Edge Shape Effect on the Flow over NonSlender Delta Wings," AIAA Paper 2008-344, January 2008.

[12] Folk, C. and Ho, C. M., "Micro-Actuators for Control of Delta Wing with Sharp Leading Edge," AIAA Paper 2001-0121, January 2001. 
[13] Verhaagen, N. G., "Effects of Leading-Edge Radius on Aerodynamic Characteristics of $50^{\circ}$ Delta Wings," AIAA Paper 2010-323, January 2010.

[14] Sun, Y. C., Experimental Investigation of the Flow Field About Sharp-Edged Delta and Rectangular Wings, M.a. sc., The University of British Columbia, 1961.

[15] Jensen, A. A., Wind tunnel investigation of a supersonic tailless airplane at low subsonic speed, Phd thesis, California Institute of Technology, 1948.

[16] Ornberg, T., "A Note on the Flow Around Delta Wings," KTH-Aero TN, 1954, pp. 961-962.

[17] Traub, L. W., "Comparative Study of Delta Wings with Blunt Leading Edges and Vortex Flaps," Journal of Aircraft, Vol. 33, No. 4, 1996, pp. 828-830, DOI: 10.2514/3.47022.

[18] Polhamus, E. C., "Prediction of Vortex-Lift Characteristics by a Leading-Edge-Suetion Analogy," Journal of Aircraft, Vol. 8, No. 4, 1971, pp. 193-199.

[19] Jones, R. T., "Properties of Low Aspect Ratio Pointed Wings at Speeds Above and Below the Speed of Sound," NACA Rept. 835, 1946.

[20] Mangier, K. W. and Smith, J. H. B., "Calculations of the Flow Past Slender Delta Wings with Leading Edge Separation," Royal Establishment, Farnborough, England, Rept. Aero. 2533, 1957.

[21] Snyder, M. H. and Lamar, J. E., "Application of the Leading-Edge Sunction Analogy to Prediction of Longitudinal Load Distribution and Pitching Moments For Sharp-Edge Delta Wings," NASA TN D-6994, 1972.

[22] Vigneron, Y. C., Rakich, J. V., and Tannehill, J. C., "Calculation of Supersonic Viscous Flow Over Delta Wings With Sharp Subsonic Leading Edges," NASA TM-78500, 1978.

[23] Marsden, D. J., Simpson, R. W., and Rainbird, W. J., "An Investigation into the Flow Over Delta Wings at Low Speeds with Leading Edge Separations." College of Aeronautics Report 114. A.R.C. 20 409, 1958.

[24] Leibovich, S., "Vortex Stability and Breakdown: Survey and Extension," AIAA Journal, Vol. 22, No. 9, 1984, pp. 1192-1206.

[25] Taylor, G. S., Schnorbus, T., and Gursul, I., "An Investigation of Vortex Flows Over Low Speed Delta Wings," AIAA Paper 2003-4021, June 2003.

[26] Pamadi, B. N., Performance, Stability, Dynamics, and Control of Airplanes, AIAA Education Series, Reston, AIAA, 2004.

[27] Cummings, R. M., Forsythe, J. R., Morton, S. A., and Squires, K. D., "Challenges in High Angle of Attack Flow Prediction," Progress in Aerospace Sciences, Vol. 39, No. 5, 2003, pp. 369-384.

[28] Rinoie, K., "Experiments on a 60-Degree Delta Wing with Rounded Leading-Edge Vortex Flaps," Journal of Aircraft, Vol. 37, No. 1, 2000, pp. 37-44, DOI: 10.2514/2.2559.

[29] Luckring, J. M., "A Survey of Factors Affecting Blunt Leading-Edge Separation for Swept and SemiSlender Wings," AIAA Paper 2010-4820, June 2010.

[30] Tomaro, R. F., Strang, W. Z., and Sankar, L. N., "An Implicit Algorithm For Solving Time Dependent Flows on Unstructured Grids," AIAA Paper 1997-0333, 1997.

[31] Grismer, M. J., Strang, W. Z., Tomaro, R. F., and Witzemman, F. C., "Cobalt: A Parallel, Implicit, Unstructured Euler/Navier-Stokes Solver," Advanced Engineering Software, Vol. 29, No. 3-6, 1998, pp. 365-373.

[32] Strang, W. Z., Tomaro, R. F., and Grismer, M. J., "The Defining Methods of Cobalt: A Parallel, Implicit, Unstructured Euler/Navier-Stokes Flow Solver," AIAA Paper 1999-0786, 1999.

[33] Godunov, S. K., "A Difference Scheme for Numerical Computation of Discontinuous Solution of Hydrodynamic Equations," Sbornik Mathematics, Vol. 47, 1959, pp. 271-306.

[34] Gottlieb, J. J. and Groth, C. P. T., "Assessment of Riemann Solvers For Unsteady One-dimensional Inviscid Flows of Perfect Gasses," Journal of Fluids and Structure, Vol. 78, No. 2, 1998, pp. 437-458.

[35] Spalart, P. R. and Allmaras, S. R., "A One Equation Turbulence Model for Aerodynamic Flows," AIAA Paper 1992-0439, January 1992.

[36] Spalart, P. R. and Shur, M. L., "On the Sensitization of Turbulence Models to Rotation and Curvature," Aerospace Science and Technology, Vol. 1, 1997, pp. 297-302.

[37] Cummings, R. M. and Schütte, A., "An Integrated Computational/Experimental Approach to UCAV 
Stability \& Control Estimation: Overview of NATO RTO AVT-161," Journal of Aircraft, Vol. 49, No. 6, 2012, pp. 1542-1557.

[38] Cummings, R. M., Jirasek, A., Petterson, K., and Schmidt, S., "SACCON Static and Dynamic Motion Flow Physics Simulation Using Cobalt," AIAA Paper 2010-4691, June-July 2010.

[39] Frank, N., "Strategy for Dynamic CFD Simulations on SACCON Configuration," AIAA Paper 20104559, June-July 2010.

[40] Vallespin, D., Da Ronch, A., Badcock, K. J., and Boelens, O., "Validation of Vortical Flow Predictions for a UCAV Wind Tunnel Model," AIAA Paper 2010-4560, June-July 2010.

[41] Tyssel, L., "Hybrid Grid Generation for Complex 3D Geometries," Proceedings of the 7th International Conference on Numerical Grid Generation in Computational Field Simulation, 2000, pp. 337-346.

[42] Tyssel, L., "The TRITET Grid Generation System," International Society of Grid Generation (ISGG)," Proceedings of the 10the International Conference on Numerical Grid Generation in Computational Field Simulations, 2000.

[43] Hövelmann, A., Grawunder, M., Buzica, A., and Breitsamter, C., "Experimental Analyses on the Flow Field Characteristics of the AVT-183 Diamond Wing Configuration," AIAA Paper 2015-0064, January 2015.

[44] Spalart, P. R., Jou, W.-H., Strelets, M., and Allmaras, S. R., "Comments on the Feasibility of LES for Wings, and on a Hybrid RANS/LES Approach," In Proceedings, 1st AFSOR International Conference on DNS/LES, Greyden Press, Columbus, OH, 1997, pp. 137147.

[45] Trapier, S., Deck, S., and Duveau, P., "Delayed Detached-Eddy Simulation and Analysis of Supersonic Inlet Buzz," AIAA Journal, Vol. 46, No. 1, 2008, pp. 118-131.

[46] Luckring, J. M. and Boelens, O. J., "A Unit-Problem Investigation of Blunt Leading-Edge Separation Motivated by AVT-161 SACCON Research," presented at the RTO Applied Vehicle Technology Panel (AVT) Specialists Meeting held in Portsmouth, United Kingdom on 12 - 14 October 2011.

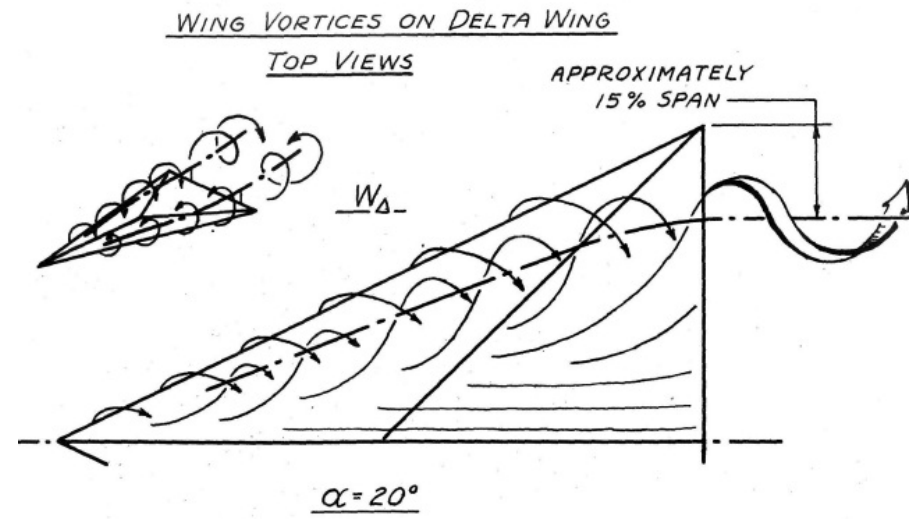

Figure 1: Jensen's sketch of leading edge vortices over a delta wing at $\alpha=20^{\circ}[15]$. 


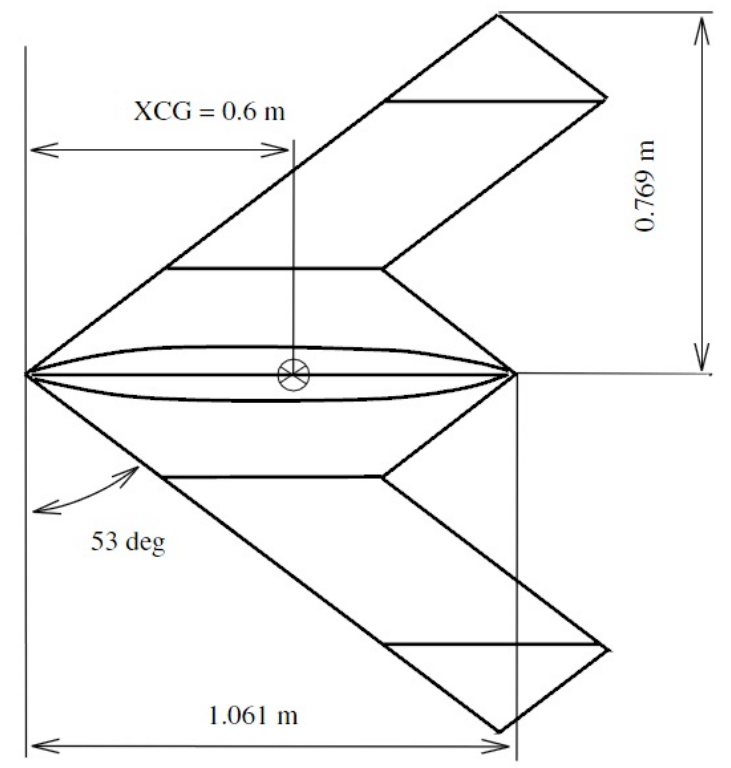

Figure 2: The SACCON geometry.

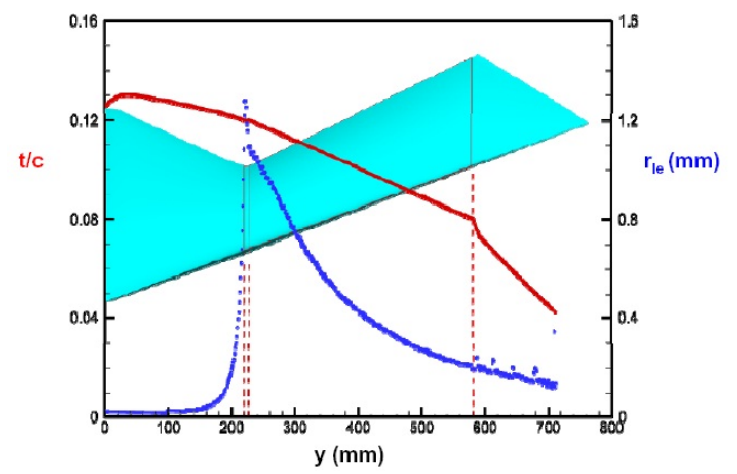

Figure 3: SACCON thickness and leading-edge radius. This picture is adapted from Ref 46 . 


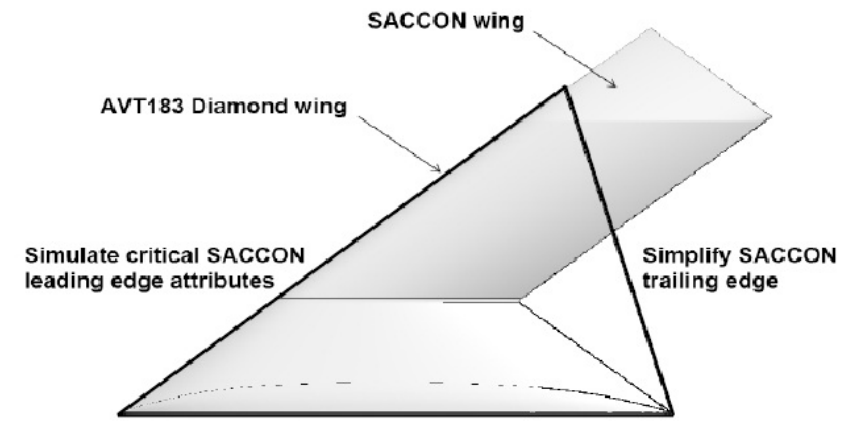

Figure 4: Diamond wing concept. This picture is adapted from Ref 46.

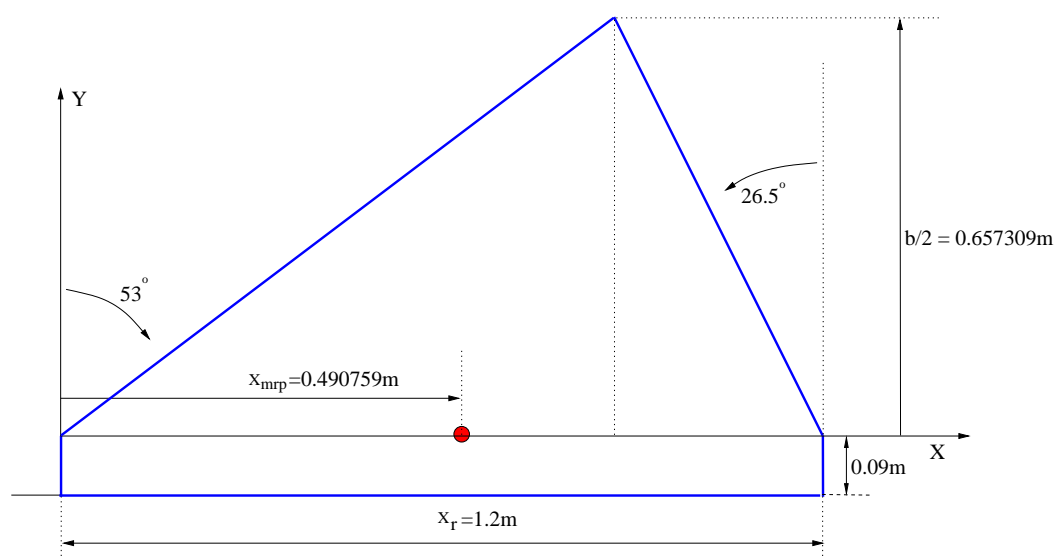

Figure 5: Diamond wing geometry 


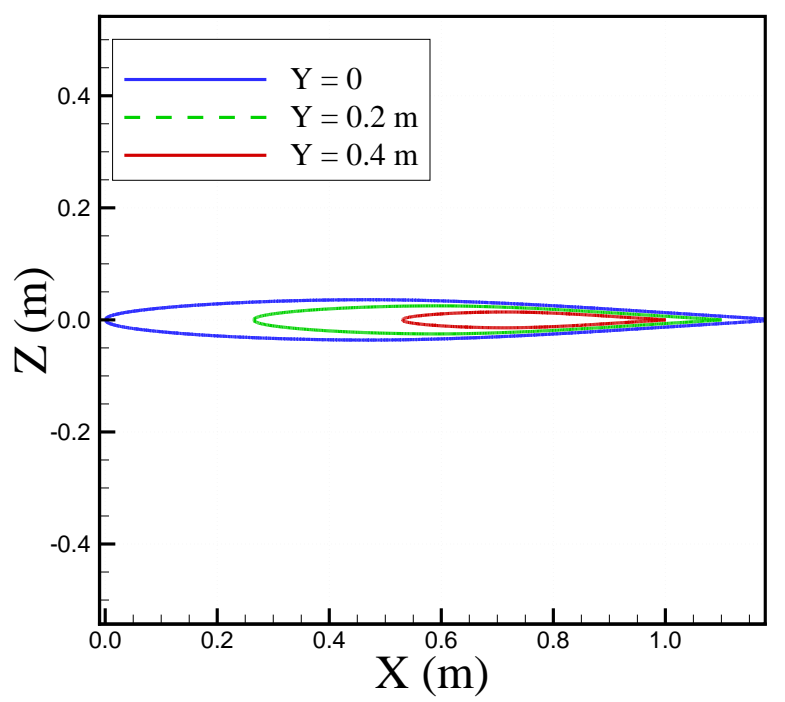

Figure 6: NACA 64A006 airfoil section used in the diamond wing.

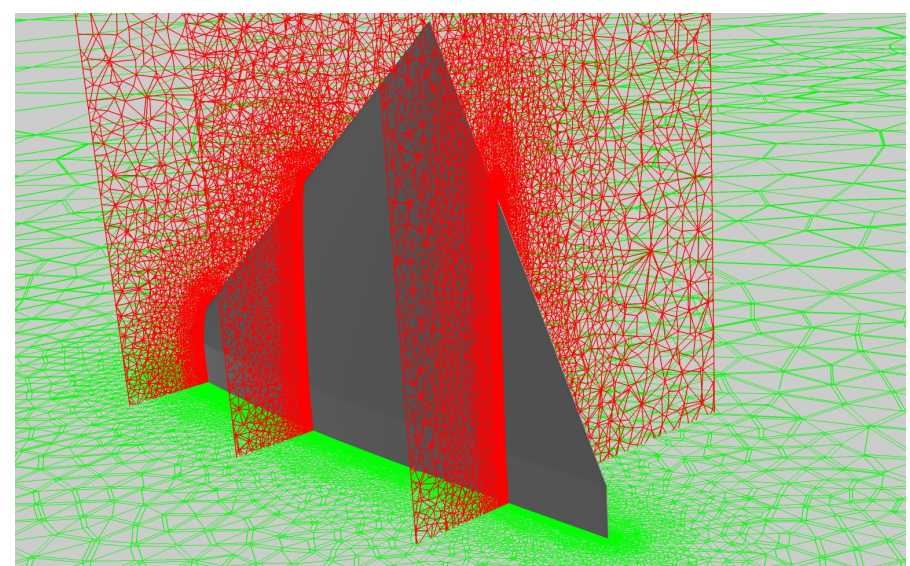

Figure 7: Diamond wing mesh. 


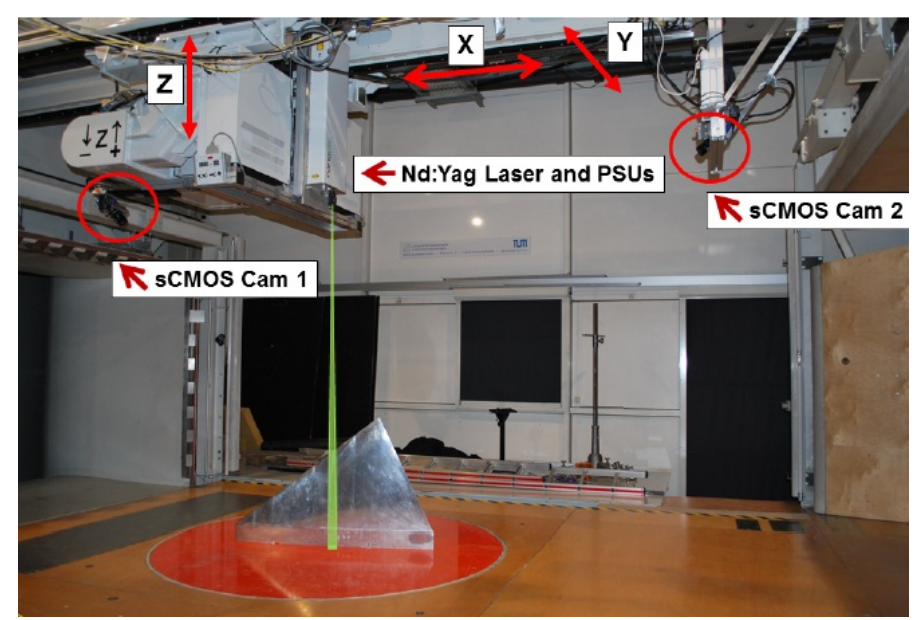

Figure 8: The AVT-183 diamond wing at the Technische Universität München wind tunnel [43].

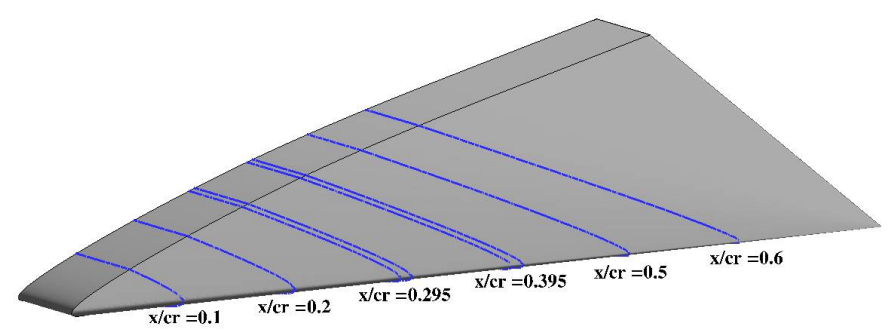

Figure 9: Pressure tap locations. Tap locations of $x / c r=0.305$ and $x / c r=0.405$ are not labeled in the picture. 


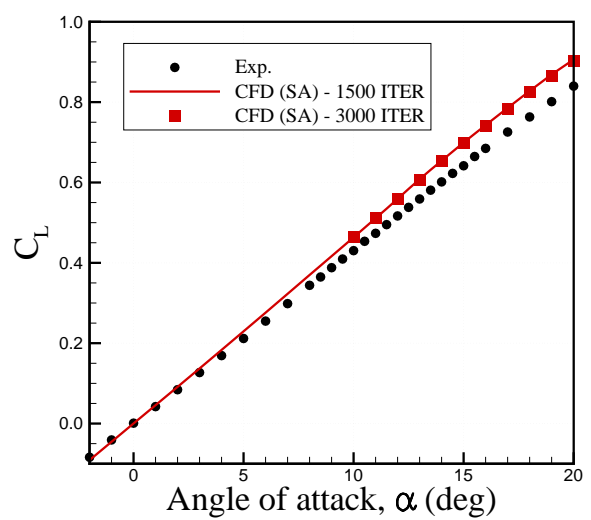

(a) Lift coefficient

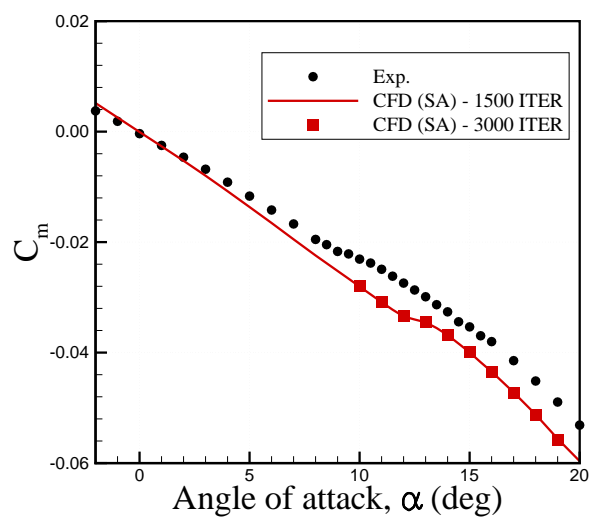

(c) Pitch-moment coefficient

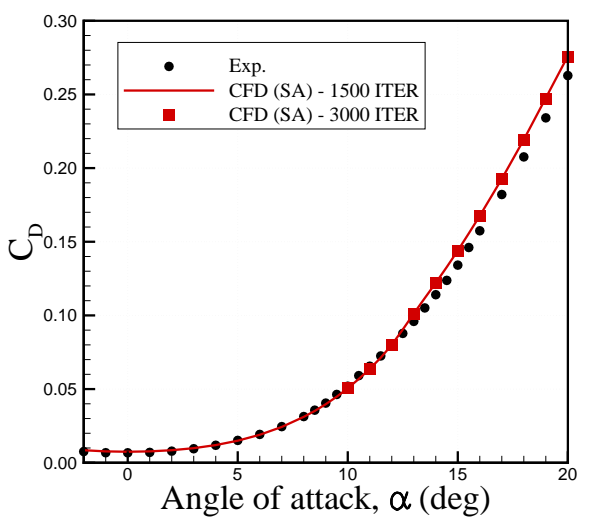

(b) Drag coefficient

Figure 10: Cobalt predictions with the SA turbulence model; $M=0.15$ and $R e=2.7 \times 10^{6}$. 


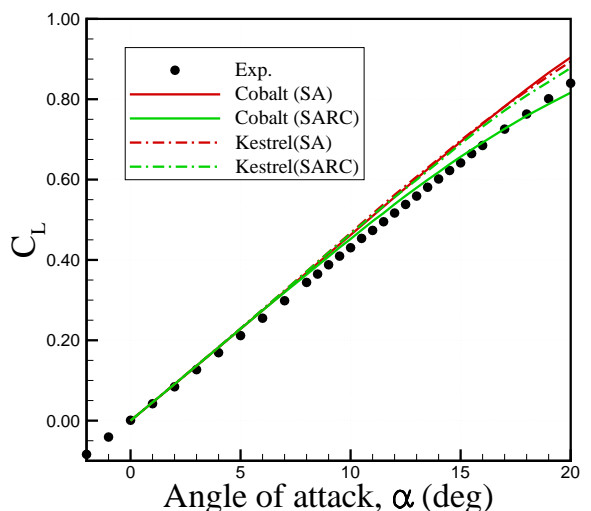

(a) Lift coefficient

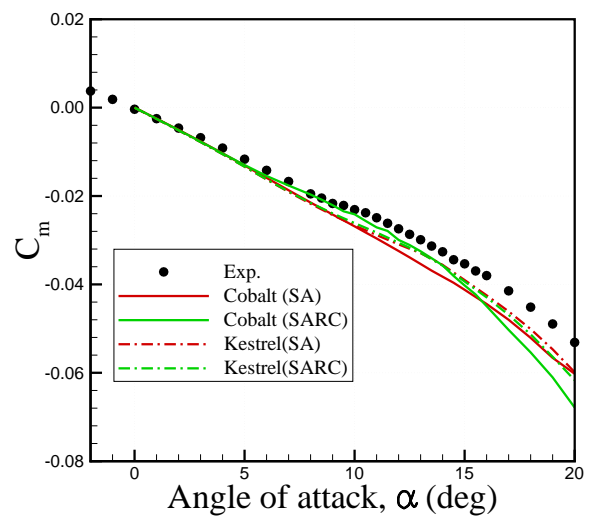

(c) Pitch-moment coefficient

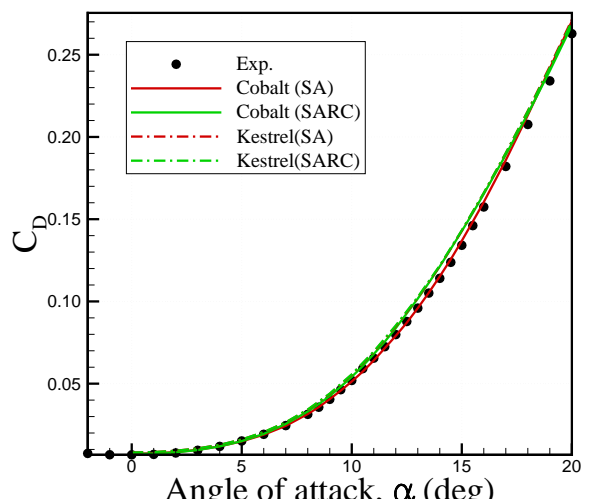

(b) Drag coefficient

Figure 11: Comparison of SARC and SA predictions using Cobalt and Kestrel codes; first-order accuracy in time with one Newton sub-iteration were used; $M=0.15$ and $R e=2.7 \times 10^{6}$. 


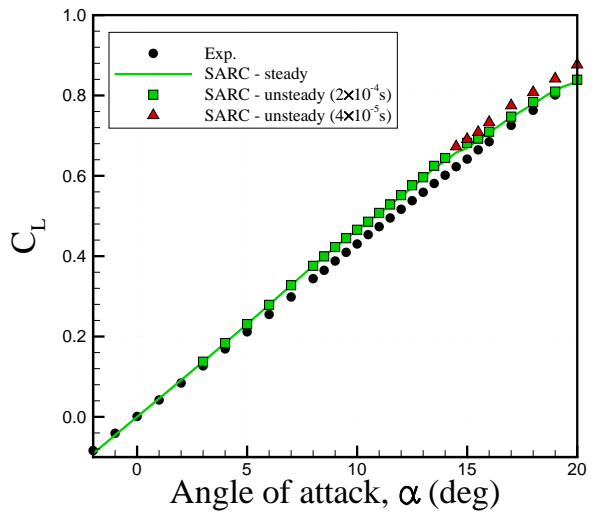

(a) Lift coefficient

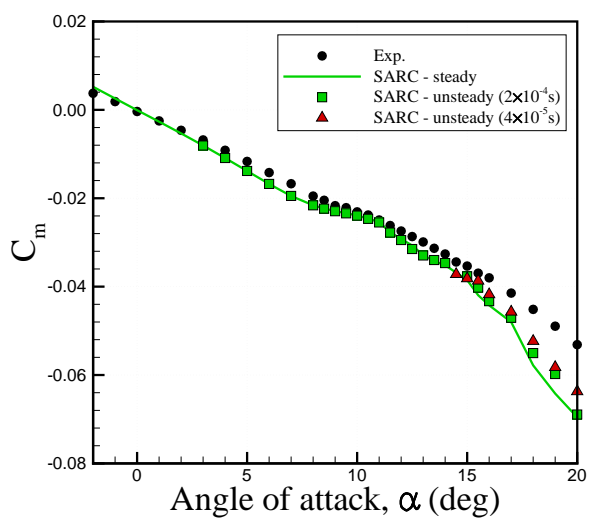

(c) Pitch-moment coefficient

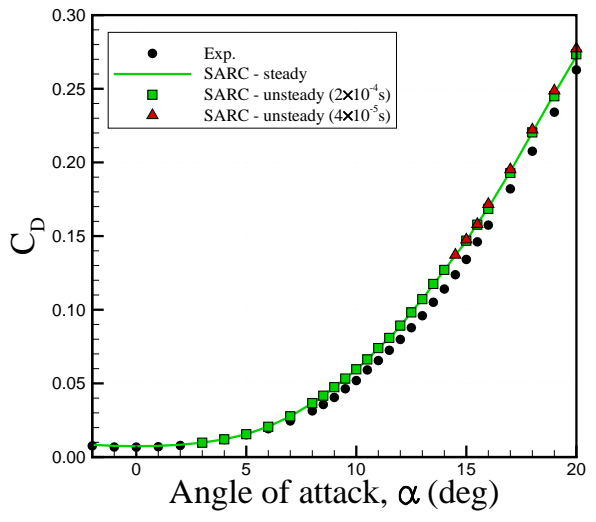

(b) Drag coefficient

Figure 12: Unsteady simulations using Cobalt and the SARC turbulence model. In all unsteady simulations, second order accuracy in time with three Newton sub-iteration were used. All unsteady coefficients are averaged values for last 3,000 iterations; $M=0.15$ and $R e=2.7 \times 10^{6}$. 


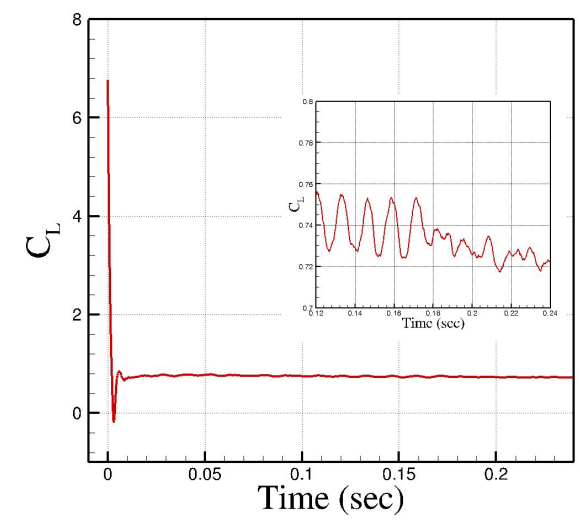

(a) Lift coefficient

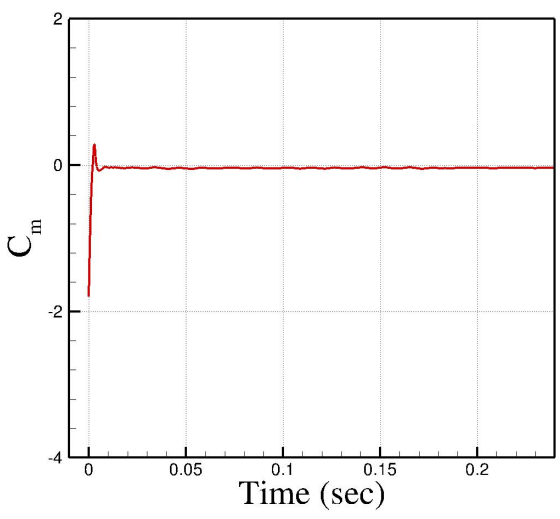

(b) Pitch-moment coefficient

Figure 13: Convergence history of unsteady simulation with $t=4 \times 10^{-5}$ seconds at $\alpha=16^{\circ}$ and using Cobalt and the SARC turbulence model.

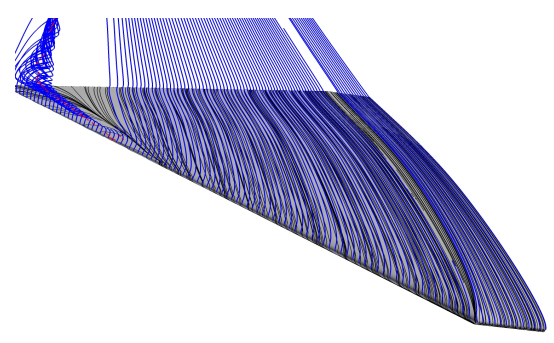

(d) $\alpha=6^{\circ}$

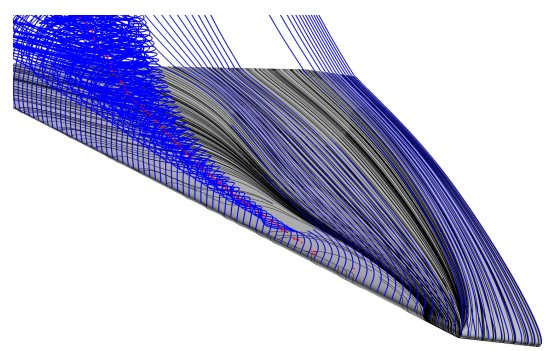

(d) $\alpha=14^{\circ}$

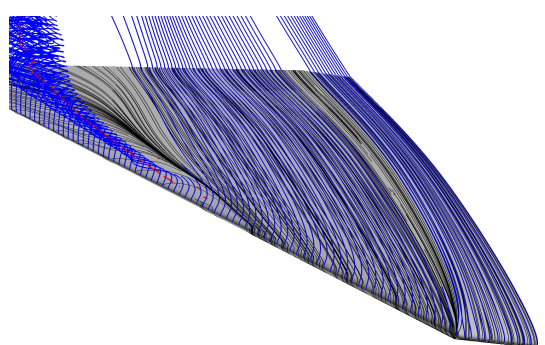

(e) $\alpha=10^{\circ}$

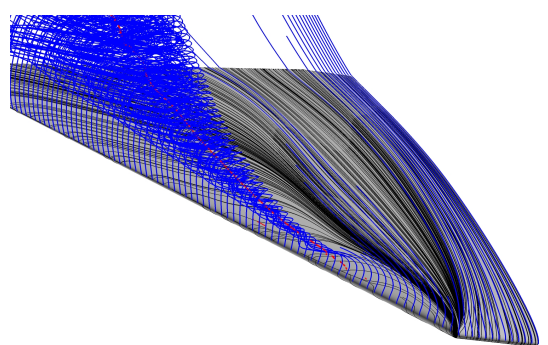

(e) $\alpha=16^{\circ}$

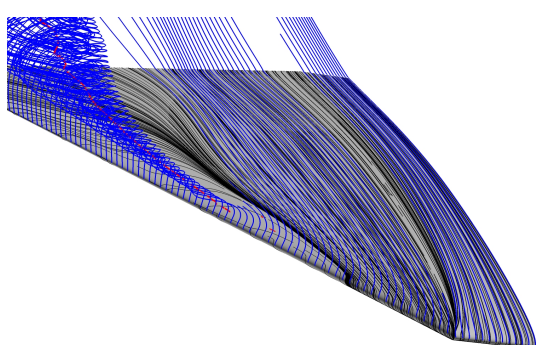

(f) $\alpha=12^{\circ}$

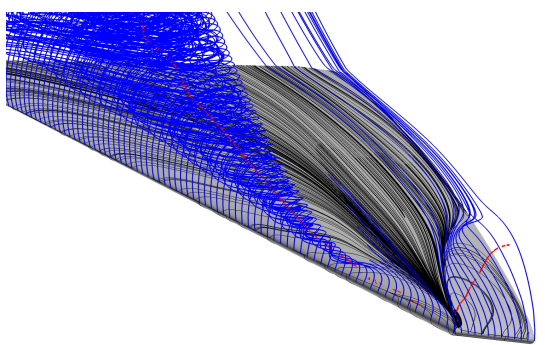

(f) $\alpha=18^{\circ}$

Figure 14: Vortical flows over the AVT-183 diamond wing using Cobalt and the SARC turbulence model. 

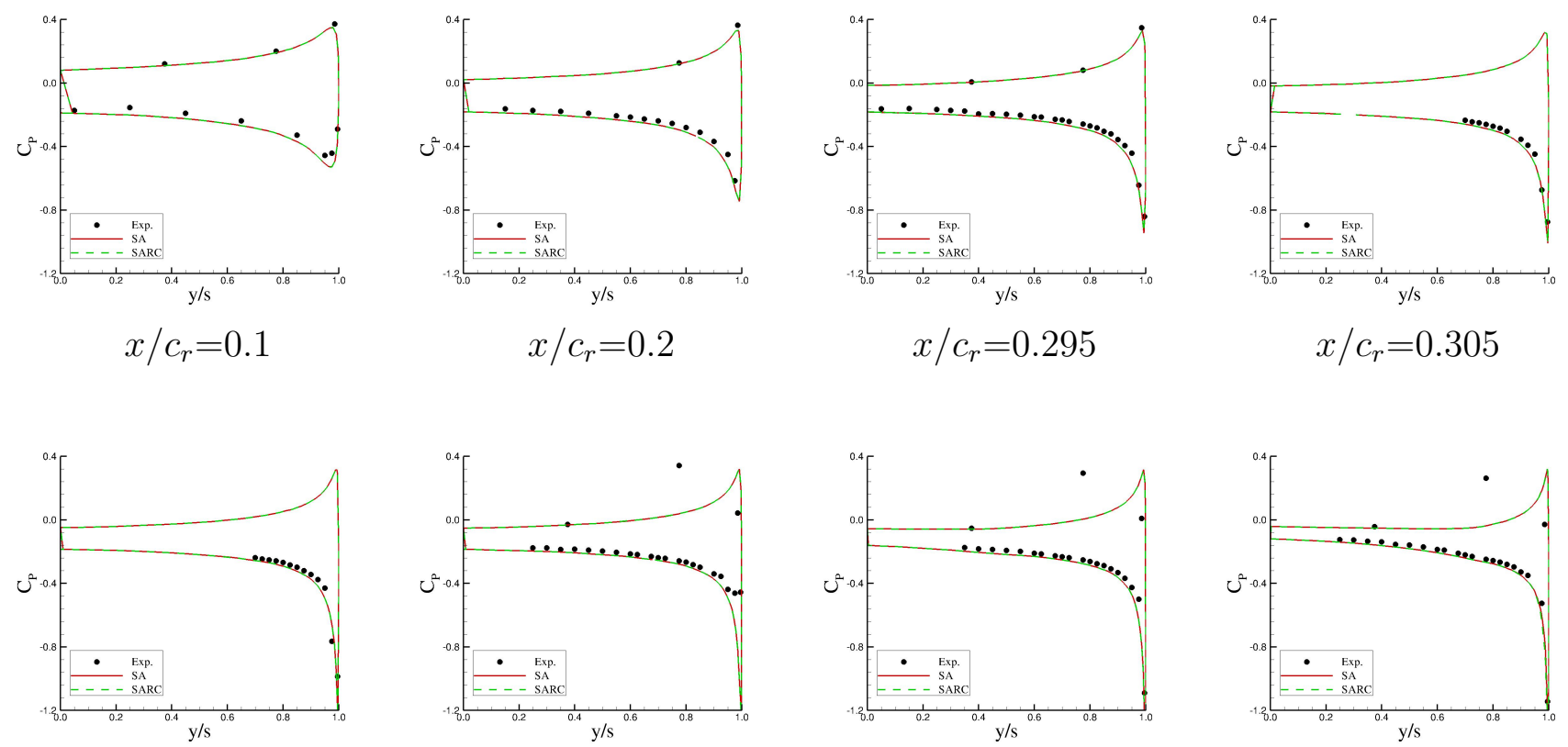

$x / c_{r}=0.395$

$x / c_{r}=0.405$

$x / c_{r}=0.5$

$x / c_{r}=0.6$

Figure 15: Comparison of SA and SARC predictions with pressure tap data at $\alpha=4^{\circ} ; M=0.15$ and $R e=2.7 \times 10^{6}$. 


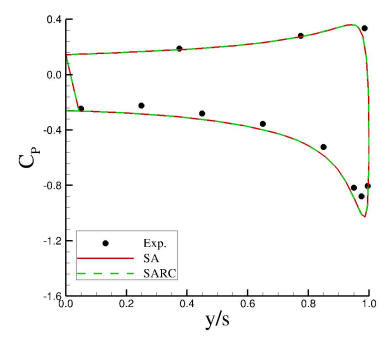

$x / c_{r}=0.1$

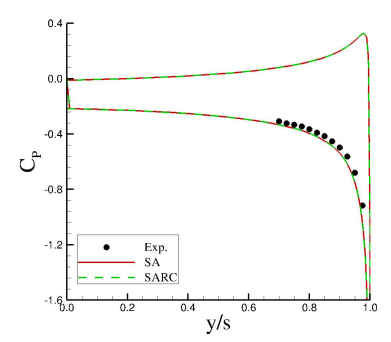

$x / c_{r}=0.395$

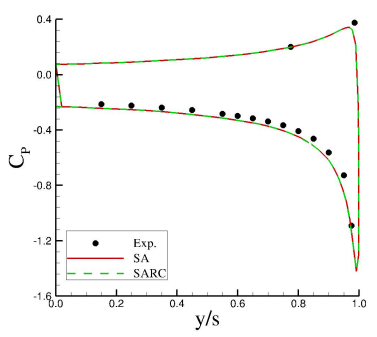

$x / c_{r}=0.2$

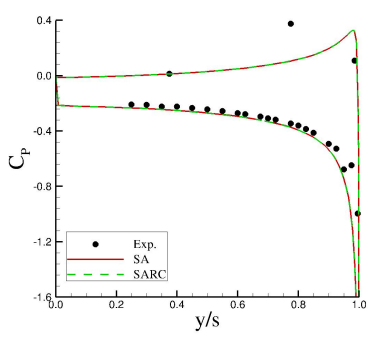

$x / c_{r}=0.405$

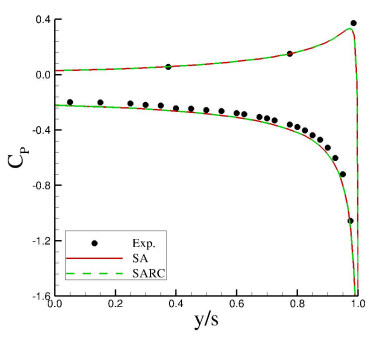

$x / c_{r}=0.295$

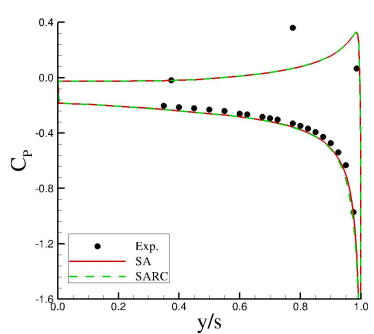

$x / c_{r}=0.5$

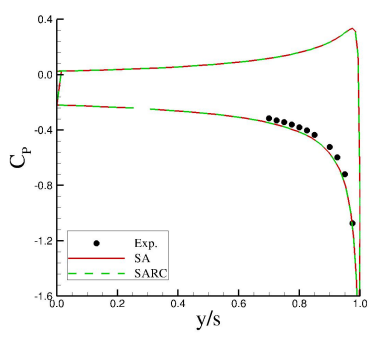

$x / c_{r}=0.305$

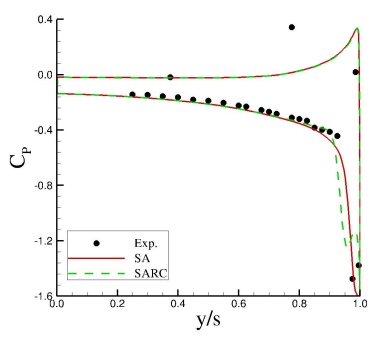

$x / c_{r}=0.6$

Figure 16: Comparison of SA and SARC predictions with pressure tap data at $\alpha=6^{\circ} ; M=0.15$ and $R e=2.7 \times 10^{6}$. 


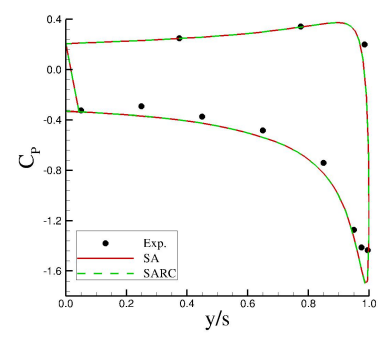

$x / c_{r}=0.1$

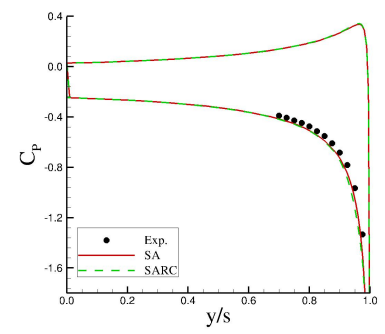

$x / c_{r}=0.395$

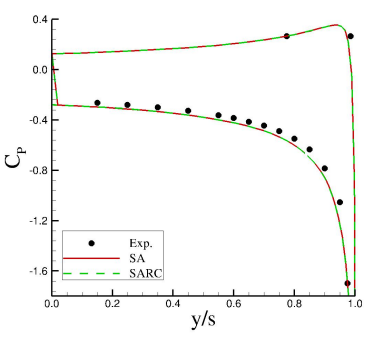

$x / c_{r}=0.2$

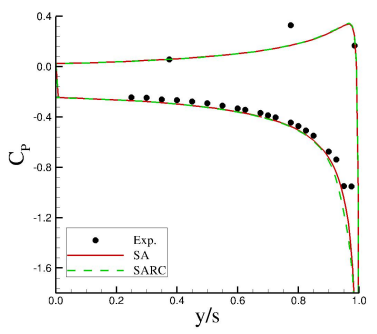

$x / c_{r}=0.405$

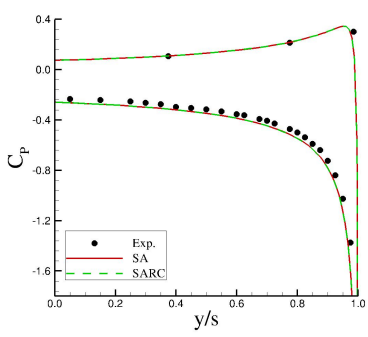

$x / c_{r}=0.295$

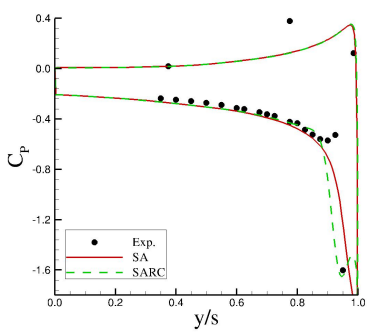

$x / c_{r}=0.5$

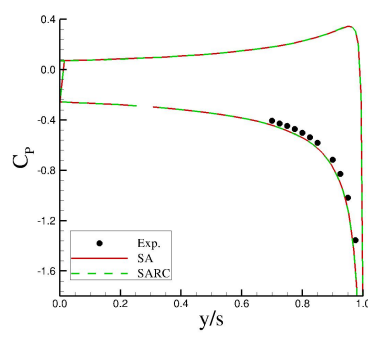

$x / c_{r}=0.305$

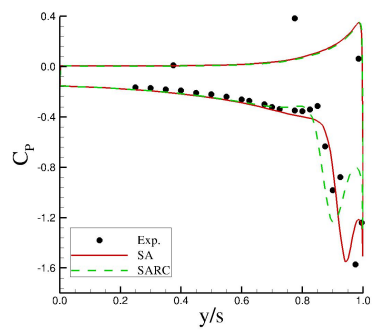

$x / c_{r}=0.6$

Figure 17: Comparison of SA and SARC predictions with pressure tap data at $\alpha=8^{\circ} ; M=0.15$ and $R e=2.7 \times 10^{6}$. 

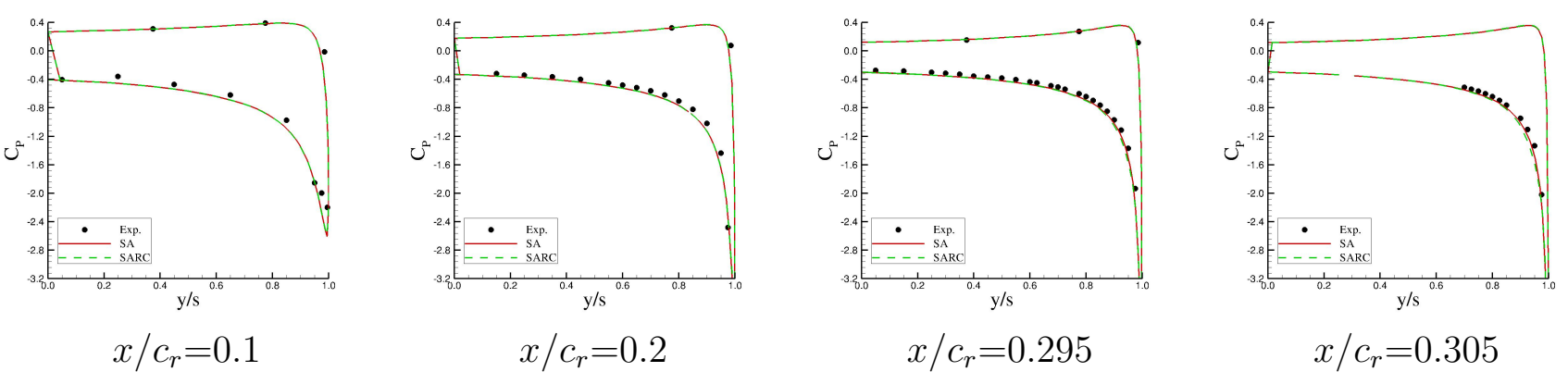

$x / c_{r}=0.2$

$x / c_{r}=0.295$

$x / c_{r}=0.305$
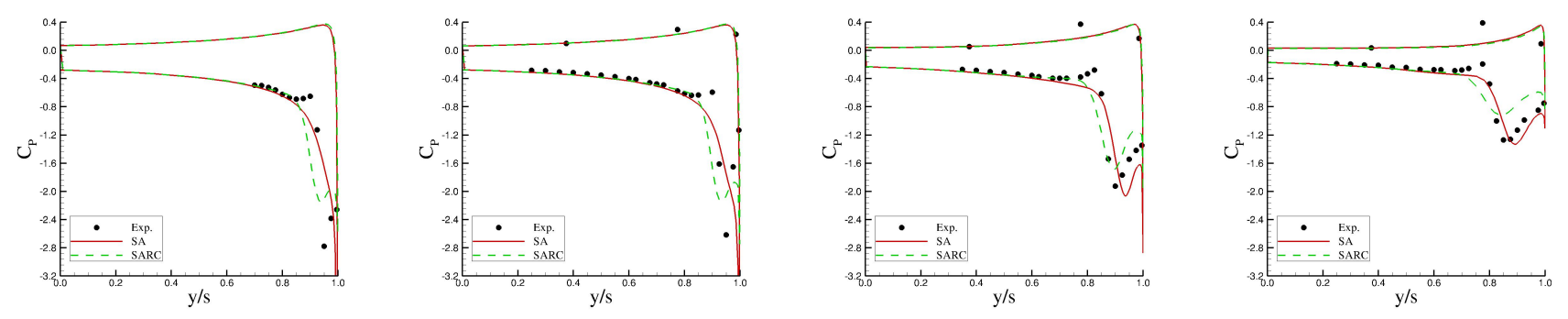

$x / c_{r}=0.395$

$x / c_{r}=0.405$

$x / c_{r}=0.5$

$x / c_{r}=0.6$

Figure 18: Comparison of SA and SARC predictions with pressure tap data at $\alpha=10^{\circ} ; M=0.15$ and $R e=2.7 \times 10^{6}$. 

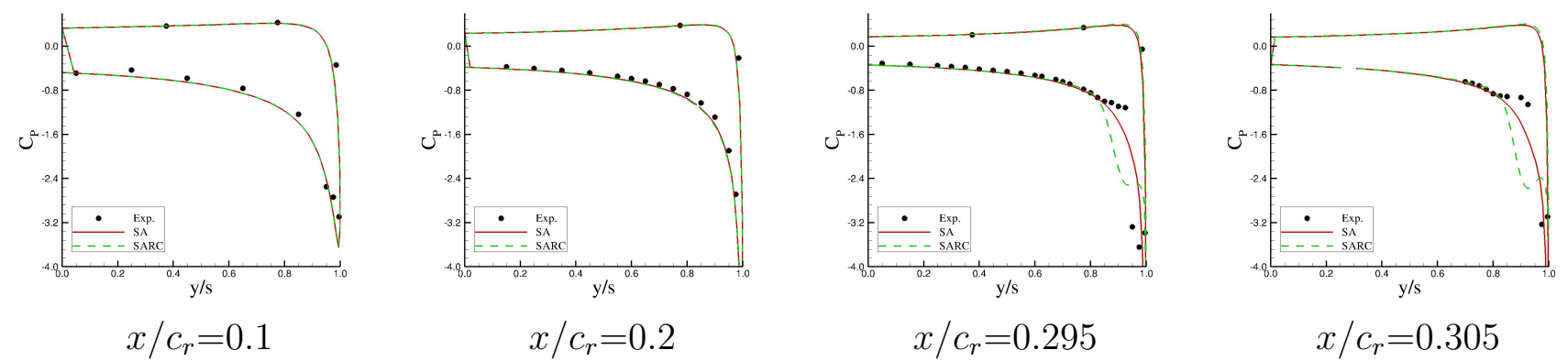

$x / c_{r}=0.2$

$x / c_{r}=0.295$

$x / c_{r}=0.305$
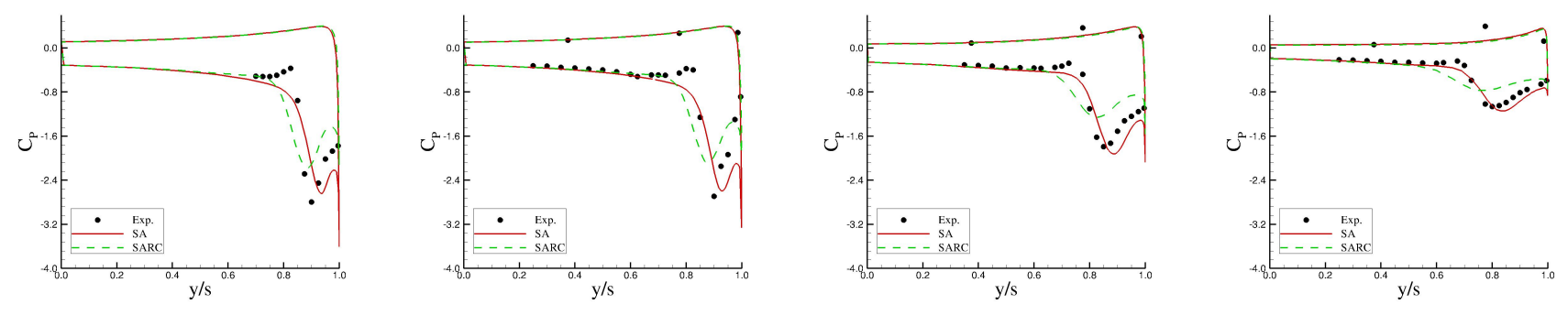

$x / c_{r}=0.395$

$x / c_{r}=0.405$

$x / c_{r}=0.5$

$x / c_{r}=0.6$

Figure 19: Comparison of SA and SARC predictions with pressure tap data at $\alpha=12^{\circ} ; M=0.15$ and $R e=2.7 \times 10^{6}$. 

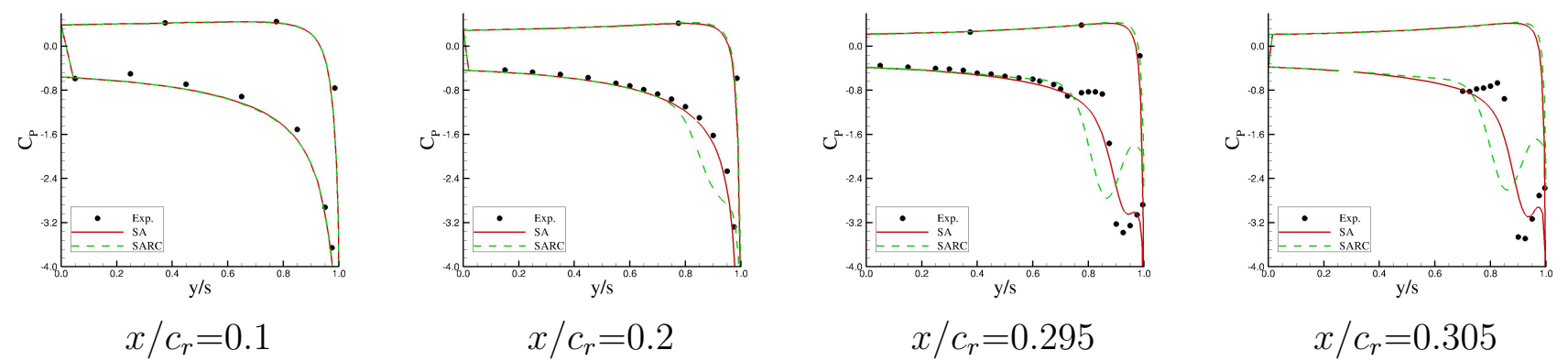

$x / c_{r}=0.2$

$x / c_{r}=0.295$

$x / c_{r}=0.305$
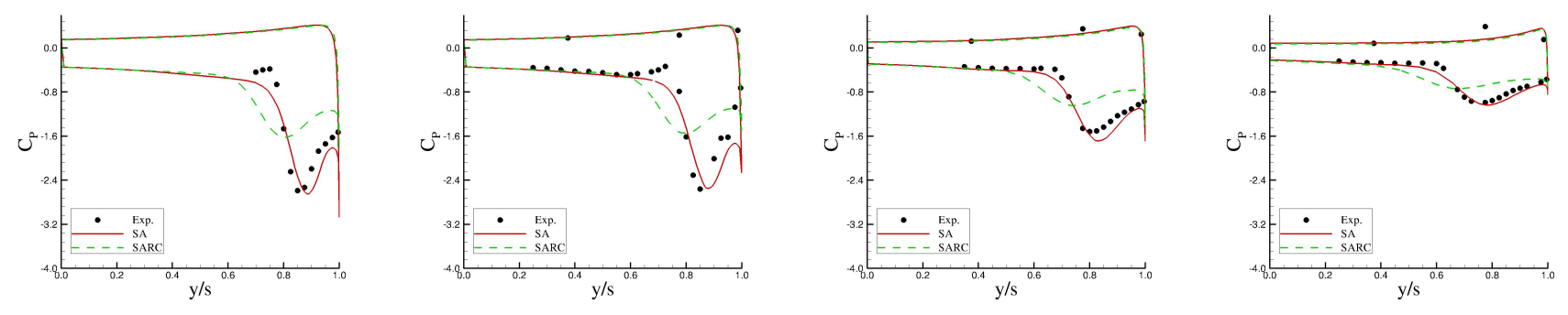

$x / c_{r}=0.395$

$x / c_{r}=0.405$

$x / c_{r}=0.5$

$x / c_{r}=0.6$

Figure 20: Comparison of SA and SARC predictions with pressure tap data at $\alpha=14^{\circ} ; M=0.15$ and $R e=2.7 \times 10^{6}$. 


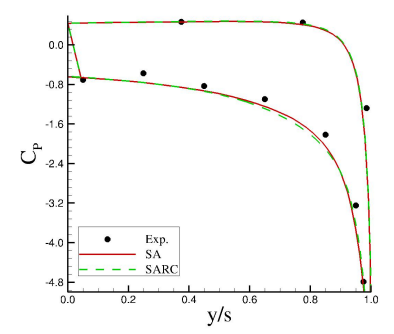

$x / c_{r}=0.1$

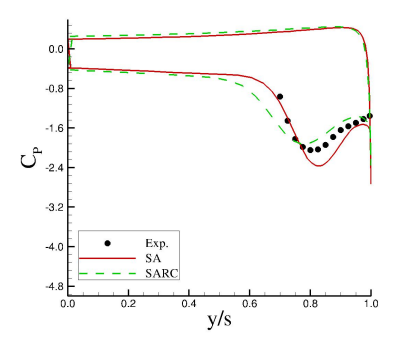

$x / c_{r}=0.395$

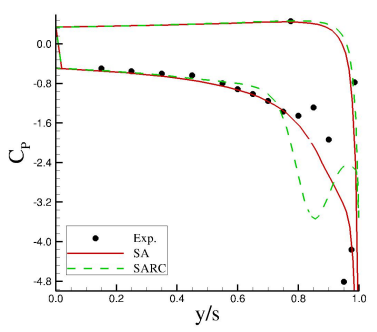

$x / c_{r}=0.2$

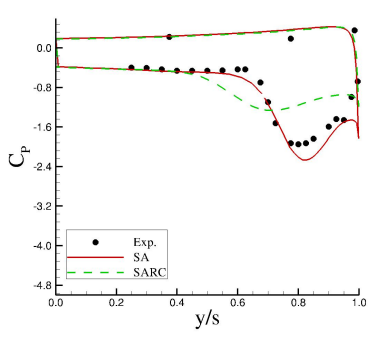

$x / c_{r}=0.405$

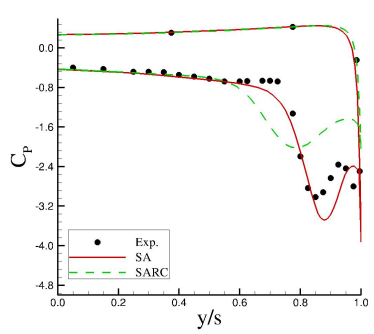

$x / c_{r}=0.295$

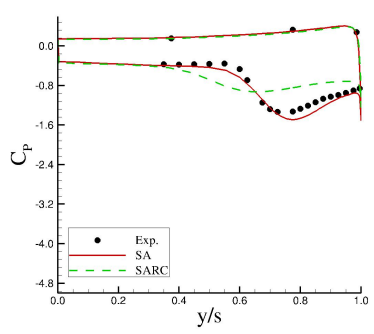

$x / c_{r}=0.5$

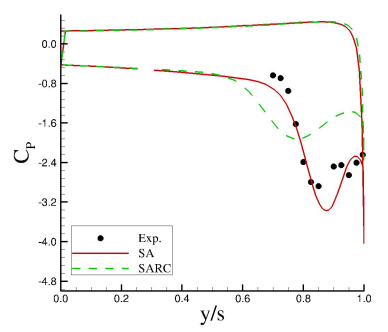

$x / c_{r}=0.305$

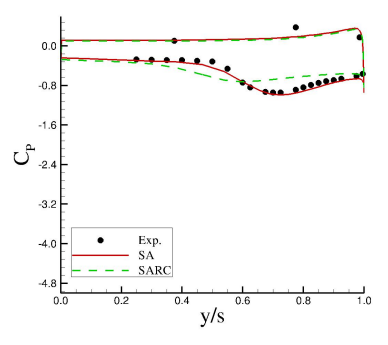

$x / c_{r}=0.6$

Figure 21: Comparison of SA and SARC predictions with pressure tap data at $\alpha=16^{\circ} ; M=0.15$ and $R e=2.7 \times 10^{6}$. 


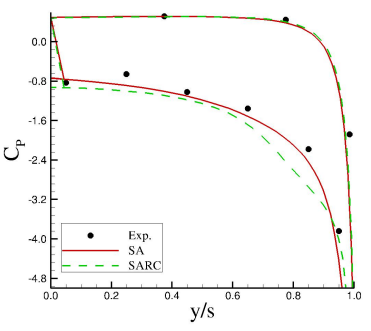

$x / c_{r}=0.1$

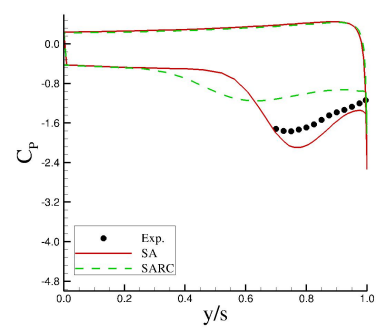

$x / c_{r}=0.395$

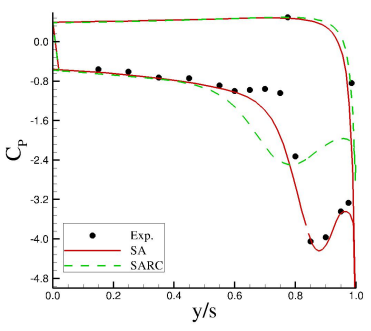

$x / c_{r}=0.2$

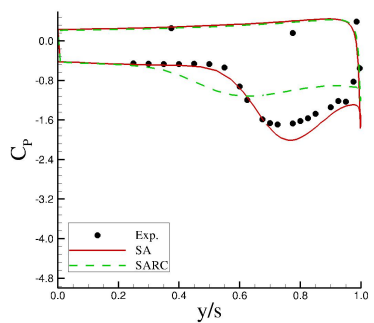

$x / c_{r}=0.405$

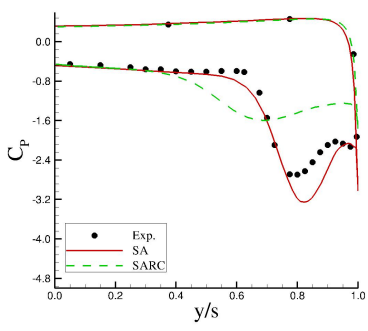

$x / c_{r}=0.295$

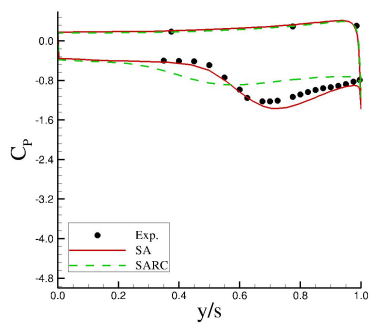

$x / c_{r}=0.5$

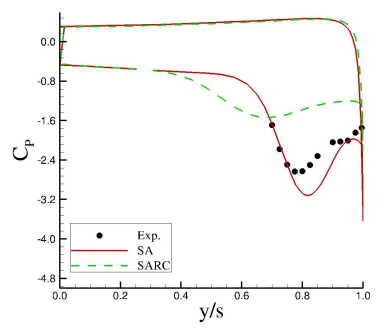

$x / c_{r}=0.305$

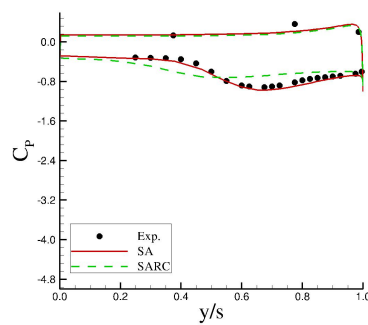

$x / c_{r}=0.6$

Figure 22: Comparison of SA and SARC predictions with pressure tap data at $\alpha=18^{\circ} ; M=0.15$ and $R e=2.7 \times 10^{6}$.

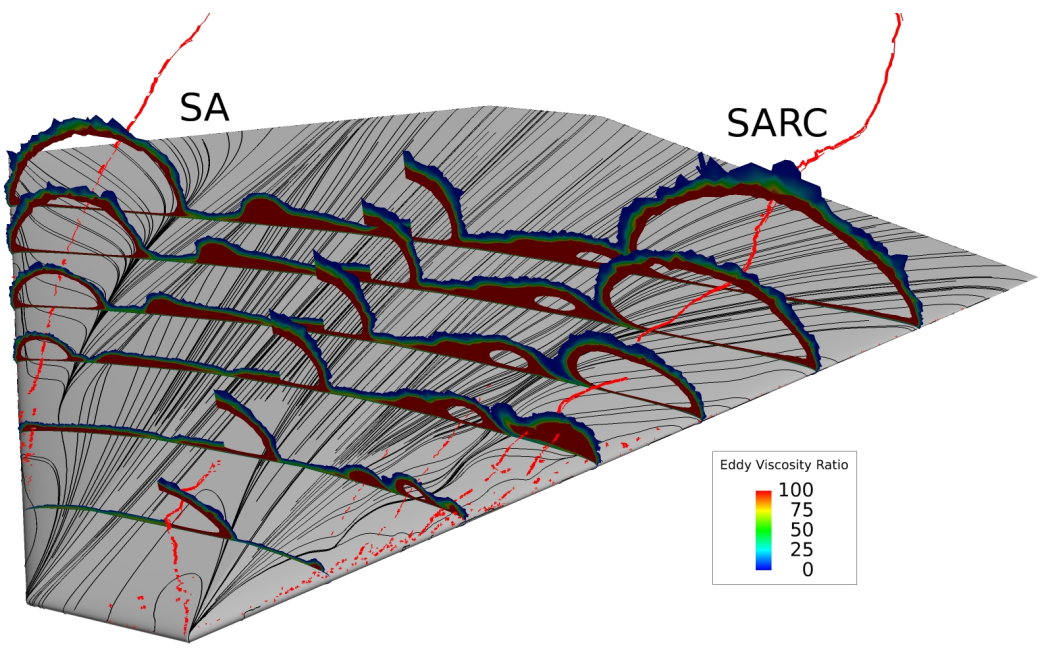

Figure 23: SA and SARC solutions in Cobalt at $\alpha=16^{\circ}$. 


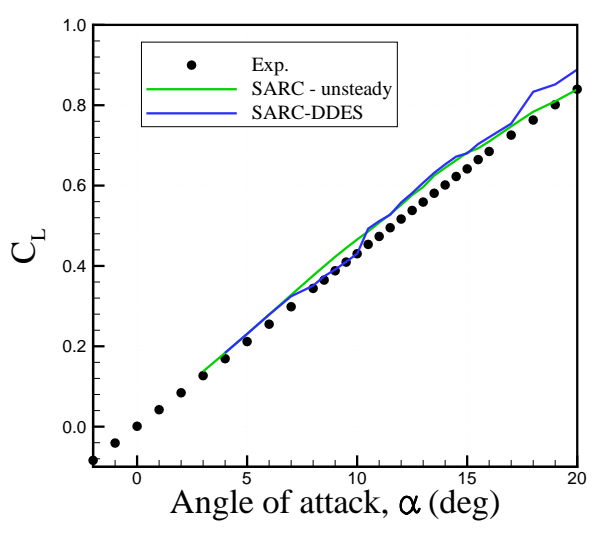

(a) Lift coefficient

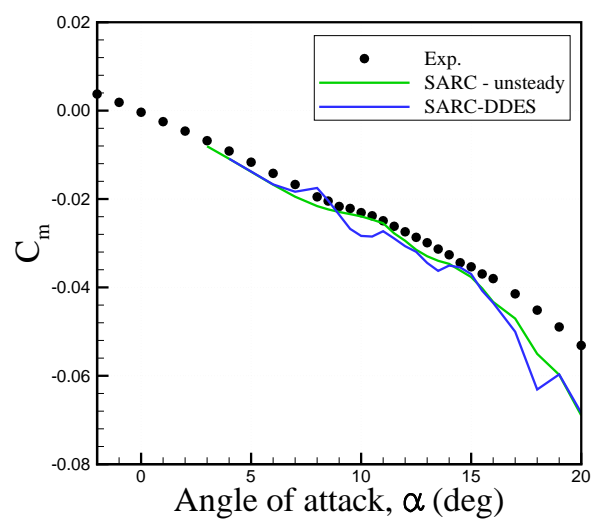

(c) Pitch-moment coefficient

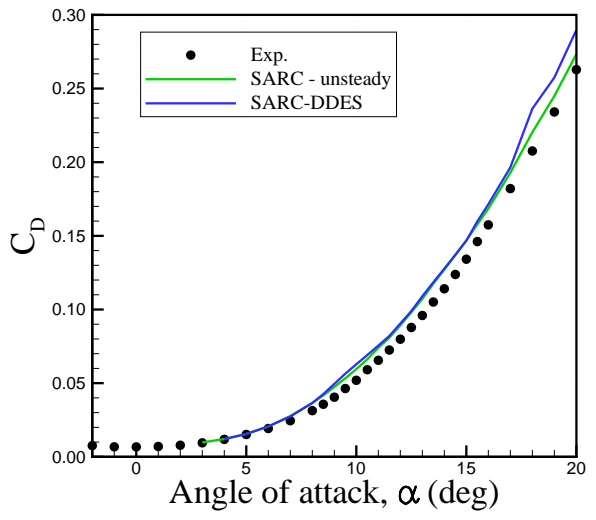

(b) Drag coefficient

Figure 24: Unsteady simulations using Cobalt with SARC-DDES turbulence model. SARC-DDES cases ran for 12,000 iterations and coefficients were averaged for last 6,000 iterations; $M=0.15$ and $R e=2.7 \times 10^{6}$. 


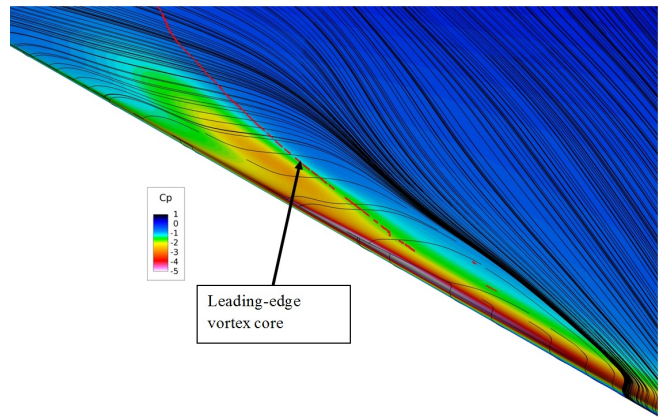

(a) Streamlines

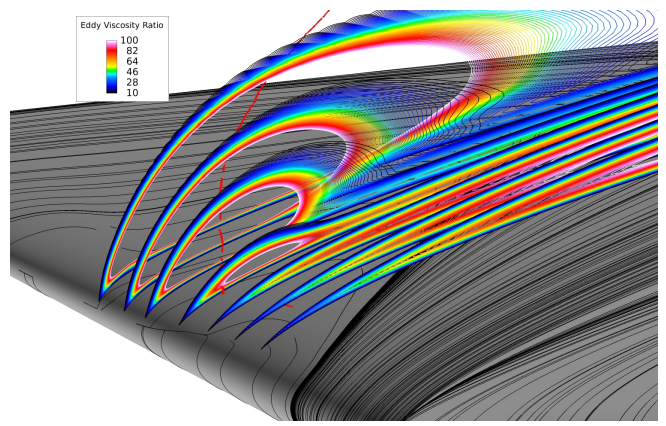

(c) Eddy viscosity ratio

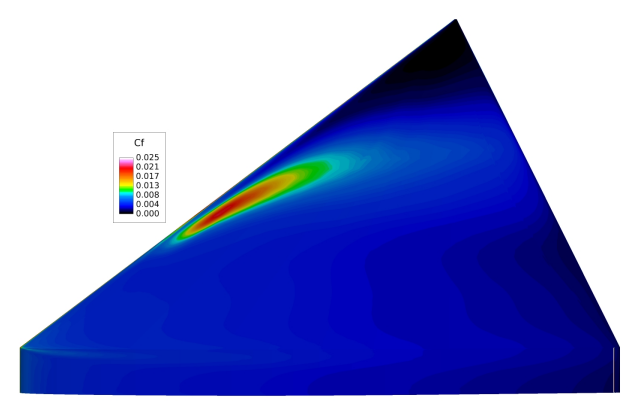

(e) Skin friction coefficient; top view

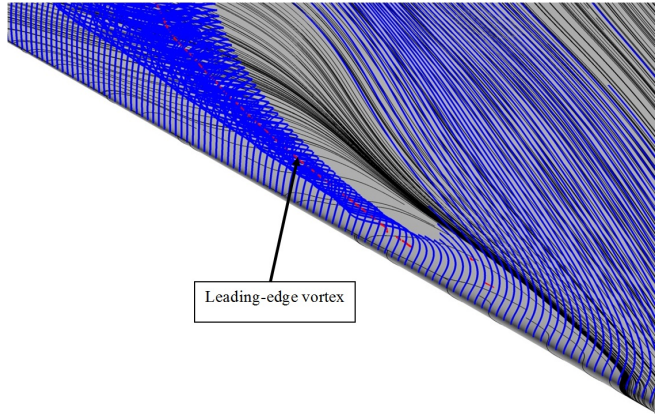

(b) Leading-edge vortex

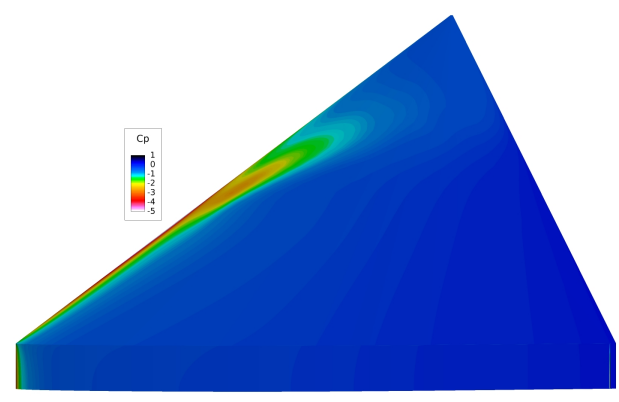

(d) Pressure coefficient; top view

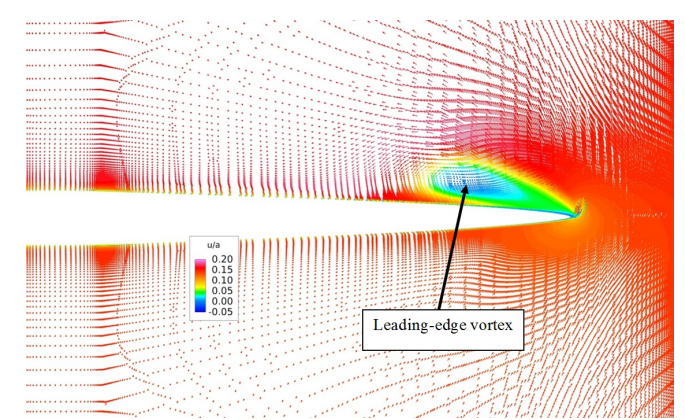

(f) $\mathrm{X}=0.7 \mathrm{~m}$

Figure 25: Flow analysis of the AVT-183 diamond wing at $\alpha=12^{\circ}$ using Cobalt and the SARC turbulence model; $M=0.15$ and $R e=2.7 \times 10^{6}$. 